\title{
Dorsally and Ventrally Derived Oligodendrocytes Have Similar Electrical Properties but Myelinate Preferred Tracts
}

\author{
Richa B. Tripathi, ${ }^{1,3 *}$ Laura E. Clarke, ${ }^{2 \star}$ Valeria Burzomato, ${ }^{2 \star}$ Nicoletta Kessaris, ${ }^{1,3}$ Patrick N. Anderson, ${ }^{3}$ \\ David Attwell, ${ }^{2}$ and William D. Richardson ${ }^{1,3}$ \\ ${ }^{1}$ Wolfson Institute for Biomedical Research, ${ }^{2}$ Research Department of Neuroscience, Physiology and Pharmacology, and ${ }^{3}$ Research Department of Cell and \\ Developmental Biology, University College London, London WC1E 6BT, United Kingdom
}

In the developing spinal cord, most oligodendrocyte precursors (OLPs) arise from the ventral ventricular zone (VZ) under the influence of Sonic Hedgehog, but a minority are generated from the dorsal VZ in a Hedgehog-independent manner. In the developing forebrain too, OLPs arise from both the ventral and the dorsal VZ. It is not known whether dorsally and ventrally derived oligodendrocyte (OL) lineage cells have different properties. We generated a dual reporter mouse line to color code ventrally and dorsally derived OLPs (vOLPs and dOLPs) and their differentiated oligodendrocyte progeny (vOLs and dOLs) for functional studies. We found that $\sim 80 \%$ of OL lineage cells in the postnatal spinal cord and $\sim 20 \%$ in the corpus callosum are ventrally derived. In both spinal cord and corpus callosum, vOLPs and dOLPs had indistinguishable electrical properties, as did vOLs and dOLs. However, vOLPs and dOLPs had different migration and settling patterns. In the spinal cord, vOLPs appeared early and spread uniformly throughout the cord, whereas dOLPs arrived later and remained mainly in the dorsal and dorsolateral funiculi. During adulthood, corticospinal and rubrospinal tracts became myelinated mainly by dOLs, even though vOLs dominated these tracts during early postnatal life. Thus, dOLPs are electrically similar to vOLPs but appear to outcompete them for dorsal axons.

\section{Introduction}

Oligodendrocytes (OLs) myelinate axons in the CNS, speeding action potentials as well as providing trophic and structural support to neurons. OLs have diverse morphologies. OLs that myelinate large-diameter axons synthesize a small number of myelin sheaths, whereas OLs that myelinate small-diameter axons can produce more than 30 sheaths (del Rio-Hortega, 1921, 1928; Bjartmar et al., 1994; Butt et al., 1994, 1997; Anderson et al., 2000; Bakiri et al., 2011). There are also molecular and physiological differences among OL lineage cells (Butt et al., 1995; Anderson, 2003; Chittajallu et al., 2004; Kleopa et al., 2004; Káradóttir et al., 2008).

Myelinating OLs develop from migratory glial precursors (OLPs) that express the proteoglycan NG2 and the plateletderived growth factor receptor $\alpha$. In the postnatal CNS, OLPs form synapse-like structures with axons ("axoglial synapses") and receive synaptic input (Khattab, 1967; Lin and Bergles, 2004; Kukley et al., 2007; Ziskin et al., 2007). Patch-clamp

Received Dec. 11, 2010; revised Feb. 26, 2011; accepted March 17, 2011.

Author contributions: N.K., D.A., and W.D.R. designed research; R.B.T., L.E.C., V.B., and P.N.A. performed research; R.B.T., L.E.C., V.B., D.A., and W.D.R. analyzed data; R.B.T., D.A., and W.D.R. wrote the paper.

${ }^{*}$ R.B.T., L.E.C., and V.B. contributed equally to this work.

This work was funded by the Wellcome Trust, the UK Medical Research Council, the National Institutes of Health, and the European Union. We thank the members of our laboratories for advice and discussions, especially Huiliang Li for helping with transgene design and construction, Ulla Dennehy for generation and maintenance of transgenic mice, and Matthew Grist for technical help. We are grateful to Michael Wegner for anti-SOX10 antibodies and to Matthew Fogarty for Msx3-Cre mice.

Correspondence should be addressed to William D. Richardson at the above addresses. E-mail: w.richardson@ucl.ac.uk.

DOI:10.1523/JNEUROSCI.6474-10.2011

Copyright $\odot 2011$ the authors $\quad 0270-6474 / 11 / 316809-11 \$ 15.00 / 0$ studies have identified two classes of OLP in white matterthose with synaptic input and voltage-gated $\mathrm{Na}^{+}$currents and others that have undetectable $\mathrm{Na}^{+}$currents (Káradóttir et al., 2008). Some of this variation might reflect developmental stage (De Biase et al., 2010; Etxeberria et al., 2010; Kukley et al., 2010; Vélez-Fort et al., 2010), although a fraction of NG2expressing OLPs lack detectable $\mathrm{Na}^{+}$currents (Káradóttir et al., 2008; Clarke et al., 2011).

In the developing mouse spinal cord, OLPs initially arise around embryonic day 12.5 (E12.5) in the ventral ventricular zone (VZ) near the floor plate (Pringle and Richardson, 1993; Sun et al., 1998). Later, around E15.5, some OLPs start to be generated in the dorsal VZ (Cai et al., 2005; Fogarty et al., 2005; Vallstedt et al., 2005). Formation of ventrally derived OLPs is Sonic Hedgehog (SHH) dependent, but dorsally derived OLPs are $\mathrm{SHH}$ independent, possibly relying on fibroblast growth factor or bone morphogenetic protein instead (for review, see Richardson et al., 2006). In the developing brain there are also dorsal and ventral sources of OLPs (Nery et al., 2001; Tekki-Kessaris et al., 2001; Kessaris et al., 2006). Are OL lineage cells that develop in different domains of the VZ identical in function, or are they different OL subtypes with specialized properties?

To address this, we engineered transgenic mice in which OL lineage cells are fluorescently labeled green or red, depending on their region of origin in the VZ. This allowed us to target ventrally and dorsally derived cells for electrophysiology. We confirmed the existence of two electrical subtypes of cells with OLP morphology - either with or without voltage-gated $\mathrm{Na}^{+}$channelsbut found no evidence that this heterogeneity was related to developmental origin. We also visualized the developmental 
spread and adult settling patterns of OLPs/OLs. Large numbers of ventrally derived OLPs invaded all parts of the spinal cord, including the most dorsal axon tracts, during the perinatal period. In the longer term, however, these dorsal tracts became populated predominantly by dorsally derived OLs. This suggests that dorsally derived OLs are better adapted for myelinating dorsal axons.

\section{Materials and Methods}

Transgenic mice. We used a $120 \mathrm{~kb}$ NotI fragment of the Sox 10 genomic PAC (RP21-427-F18), which includes $60 \mathrm{~kb}$ upstream and $50 \mathrm{~kb}$ downstream of Sox 10. The genomic region spanning exons 3-5 was replaced by loxP-eGFP-polyA-loxP-tdTomato-frt-Cm ${ }^{R}$-frt by homologous recombination in Escherichia coli (Lee et al., 2001). The $\mathrm{Cm}^{R}$ cassette was removed by transient activation of Flp recombinase with arabinose. Ten founders were generated by pronuclear injection, eight of which transmitted the transgene in roughly Mendelian ratios and expressed GFP strongly in the expected pattern. One male founder was used to establish a line for further study. These Sox10-GFP/tdTom mice were crossed to Gsh2-iCre, Msx3-iCre, or Emx1-iCre lines (Fogarty et al., 2005; Fogarty, 2006). In Sox $10^{+}$cells that express Cre recombinase, the eGFP-polyA cassette is removed, activating expression of $t d$ Tom instead (Figs. 1, 2).

Mice were kept on a $12 \mathrm{~h}$ dark/light cycle. For timed matings, breeding pairs were caged together overnight. Noon on the day of the vaginal plug was designated E0.5. The day of birth $(\sim$ E18.5) was designated postnatal day 0 (P0). Adult mice used in this study were aged P63 to P72, referred to collectively as P67.

Genotyping. Mice carrying the Sox10-GFP/tdTom transgene were identified visually by GFP fluorescence under a UV light source between P0 and P4. The full genotypes were confirmed by PCR using the following primers (forward/reverse, $5^{\prime}$ to $3^{\prime}$ ): $t d$ Tom, GCCACGAGTTCGAGATCGAG/GGCTTCTTGGCCATGTAGATGG; Emx1-Cre, GCCAAGGATGACTCTGGGCA/GCGGTGGCCAAAGAAGCGATTCCG; Gsh2-Cre, TTGGCGCGCCTGTGAAGCGTTGGACAGAGGCCC/AGGTACAGGAGGTAGTCCCTC; Msx3-Cre, GAAACCTGGACTCTGAGACTGGG/GGCTGTCCAATAACCGAAGACG.

Electrophysiology. Whole-cell recordings were made at room temperature $\left(\sim 23^{\circ} \mathrm{C}\right)$ from OLPs and OLs that expressed GFP or tdTom in the white matter of longitudinal P6-P14 spinal cord slices (thickness 150$160 \mu \mathrm{m}$ ) or the corpus callosum of P9-P12 coronal forebrain slices (225 $\mu \mathrm{m})$, made with a vibratome. Recordings were made from Msx3-Cre: Sox10-GFP/tdTom spinal cord (dorsally derived OL lineage cells red, ventrally derived cells green) and Gsh2-Cre: Sox10-GFP/tdTom forebrain (dorsally derived cells green, ventrally derived cells red). Both male and female animals were examined and no obvious differences were observed (for corpus callosum, 7 males and 9 females were examined; for spinal cord, 14 males and 17 females). In particular, there were no statistically significant differences within males or within females for the numbers of internodes myelinated by dOLs or vOLs, nor for the fraction of dOLPs or vOLPs that showed voltage-gated $\mathrm{Na}^{+}$current (either in corpus callosum or spinal cord), nor was there any difference in these parameters when comparing between males and females for dorsally or ventrally derived cells alone. Dissection and slicing of both the brain and the spinal cord were performed in ice-cold Krebs' solution containing the following (in mM): $124 \mathrm{NaCl}, 26 \mathrm{NaHCO}_{3}, 1 \mathrm{NaH}_{2} \mathrm{PO}_{4}, 2.5 \mathrm{KCl}, 2 \mathrm{MgCl}_{2}, 2.5$ $\mathrm{CaCl}_{2}, 10$ glucose, and $1 \mathrm{Na}$-kynurenate, $\mathrm{pH} 7.4$ (bubbled with $95 \%$ $\left.\mathrm{O}_{2} / 5 \% \mathrm{CO}_{2}\right)$. Slices were stored in a chamber filled with the same solution at $\sim 23^{\circ} \mathrm{C}$. OLPs were distinguished from differentiated OLs by morphology (OLPs are bipolar/stellate cells, OLs have long processes aligned with axons) and the change in membrane current induced by changing the cell membrane potential from -110 to $+30 \mathrm{mV}$ in $20 \mathrm{mV}$ steps. The steady-state $I-V$ plots are approximately ohmic (linear) with mild outward rectification for mature OLs and more outwardly rectifying for OLPs (Figs. 3, 4).

Electrodes were pulled from thick-walled borosilicate glass (GC150F10 , Harvard Apparatus) to a resistance of $6-9 \mathrm{M} \Omega$ and filled with a K-gluconate-based solution containing the following (in $\mathrm{mM}$ ): 130 K-gluconate, $4 \mathrm{NaCl}$, $0.5 \mathrm{CaCl}_{2}$, $10 \mathrm{HEPES}, 10$ BAPTA, 4 MgATP, 0.5
$\mathrm{Na}_{2} \mathrm{GTP}$, and $2 \mathrm{~K}$-Lucifer yellow (or 0.052 Alexa Fluor 568), pH 7.3 (adjusted with $\mathrm{KOH}$ ). The superfusion solution (bubbled with $\mathrm{O}_{2}$ ) contained the following (in mM): $144 \mathrm{NaCl}, 2.5 \mathrm{KCl}, 2.5 \mathrm{CaCl}_{2}, 10 \mathrm{HEPES}, 1$ $\mathrm{NaH}_{2} \mathrm{PO}_{4}$, and 10 glucose, $\mathrm{pH} 7.4$ (adjusted with $\mathrm{NaOH}$ ). Drugs (NMDA $60 \mu \mathrm{M}$, kainate $100 \mu \mathrm{M}$, and GABA $100 \mu \mathrm{M}$ ) were applied in the superfusion solution.

Data analysis and statistics. Data are presented as mean \pm SEM. Twosample equal variance $t$ tests were used to assess significance, without correction for multiple comparisons between different types of dorsally and ventrally derived cells (see Results). Two-sample KolmogorovSmirnov tests were used to compare the distribution of the number of internodes between dOLs and vOLs (see Results). The membrane resistance $\left(R_{\mathrm{m}}\right)$ and capacitance $\left(C_{\mathrm{m}}\right)$ of OLPs were estimated by fitting the transient current elicited by a voltage step to a single exponential. For mature OLs, the transient current could not be fitted satisfactorily with only one exponentially decaying component. We therefore measured the initial value of the transient current evoked by the voltage step, from which the pipette series resistance was calculated, and the steady-state current, from which the sum of the membrane and series resistances was calculated. Taking the difference between the two values, we obtained the cell membrane resistance.

Tract tracing. The anterograde tracer biotinylated dextran amine (BDA, Invitrogen) was used to label the corticospinal tract (CST) and the rubrospinal tracts (RSTs) in Msx3-Cre: Sox10-GFP/tdTom mice (Hossain-Ibrahim et al., 2007). The mice (P51-P64) were anesthetized and the skull opened; then, $10 \%(\mathrm{w} / \mathrm{v})$ solution of BDA in $0.1 \mathrm{M}$ PBS was injected using stereotactic apparatus in the right primary motor cortex (4 sites, $0.4 \mu \mathrm{l}$ at each site) and the right red nucleus ( $2 \mu \mathrm{l}$ at one site) to label the CST and RSTs, respectively. The mice were humanely killed $12 \mathrm{~d}$ after BDA injection (P63-P72, referred to as P67).

Tissue processing. Postnatal $(\mathrm{P} 7-\mathrm{P} 13)$ and adult $(>\mathrm{P} 60)$ mice were fixed by intracardiac perfusion with cold $4 \%(\mathrm{w} / \mathrm{v})$ paraformaldehyde (PFA) in $0.1 \mathrm{M}$ PBS and the brains and spinal cords were removed. The tissue was postfixed overnight in $4 \%$ PFA at $4^{\circ} \mathrm{C}$, then cryoprotected with $20 \%(\mathrm{w} / \mathrm{v})$ sucrose for $24-48 \mathrm{~h}$, and finally embedded and frozen in OCT medium and stored at $-80^{\circ} \mathrm{C}$ until needed. Spinal cords and brains were sectioned at $30 \mu \mathrm{m}$ nominal thickness and collected by floating on $0.1 \mathrm{M}$ PBS.

Immunocytochemistry and microscopy. Floating brain and spinal cord sections were pretreated with blocking solution $[10 \%(\mathrm{v} / \mathrm{v})$ sheep serum, $0.1 \%(\mathrm{v} / \mathrm{v})$ Triton X-100 in PBS] and incubated with primary antibodies overnight at $4^{\circ} \mathrm{C}$ and then secondary antibodies for $1 \mathrm{~h}$ at $20-25^{\circ} \mathrm{C}$. Primary antisera were guinea pig anti-SOX10 (a gift from M. Wegner, University of Erlangen, Erlangen, Germany; 1:2000 dilution in PBS), rat anti-GFP (Fine Chemical Products, 1:3000), rabbit anti-Olig2 (Millipore, 1:700), and mouse monoclonal CC-1 (anti-adenomatous polyposis coli, APC) (Calbiochem, 1:200). Secondary antibodies were donkey antirat Alexa 488 (1:500), goat anti-rabbit Alexa 647, goat anti-mouse IgG2b Alexa 647, donkey anti-guinea pig Cy3 (Millipore, 1:500), or (to discriminate from tdTom fluorescence) goat anti-guinea pig Alexa 647. BDA was detected by application of Streptavidin-Alexa 647 for $1 \mathrm{~h}$ at $20-25^{\circ} \mathrm{C}$. Alexa antibodies (Invitrogen) were used at 1:1000 dilution unless otherwise stated. Cell nuclei were visualized by poststaining with Hoechst 33258 (Sigma, 1:1000). tdTom was visualized by intrinsic fluorescence (excitation wavelength $554 \mathrm{~nm}$, emission $581 \mathrm{~nm}$ ), which remained stable for weeks at $4^{\circ} \mathrm{C}$ following PFA fixation. Sections were transferred to Superfrost Plus slides and dried in air, mounted in DAKO mounting medium under coverslips and examined in a PerkinElmer Ultraview or Leica TCS SPE confocal microscope. For cell counts in the corpus callosum, at least three sections per animal were examined. For cell counts in the dorsal funiculus, three sections at each spinal level (cervical, thoracic, and lumbar) were examined. This was because the corticospinal axons are still extending caudally during early postnatal development. For cell counts in the rubrospinal tract and ventral funiculus, three sections at cervical level only were examined. Data are quoted as mean $\pm \operatorname{SEM}(n=$ number of mice). The length of the cervical spinal cord (C1-C8) was measured in fixed, dissected spinal cords at P13 (5.3 $\pm 0.4 \mathrm{~mm})$ and P67 $(8.0 \pm 0.1 \mathrm{~mm})$. No statistical comparisons between males and females 
A
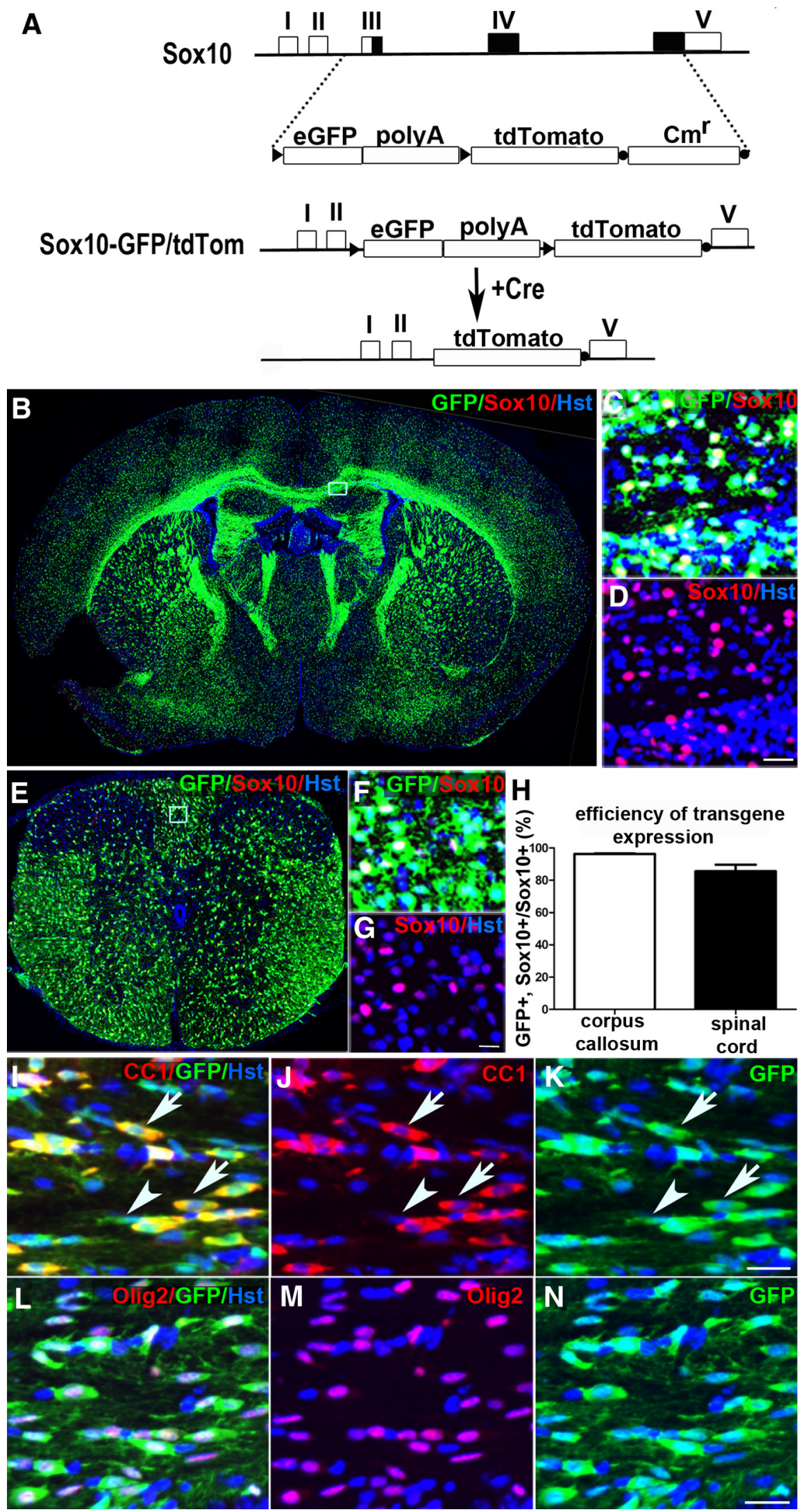

Figure 1. Generation and characterization of Sox10-GFP/tdTom dual reporter mice. $\boldsymbol{A}$, The genomic region on the Sox10 genomic PAC between exons 3 and 5 was replaced with loxP-eGFP-(polyA) ${ }_{4}$-loxP-tdTom-frt- $C \mathrm{~m}^{R}$-frt. The chloramphenicol resistance cassette $\left(\mathrm{Cm}^{R}\right)$ was removed with Flp-recombinase (Lee et al., 2001). In the absence of (re recombinase, only GFP is expressed since the ( $p o l y A)_{4}$ cassette effectively directs cleavage of the primary RNA transcript upstream of $t d T o m$. In the presence of (re, eGFP-(polyA) 4 is excised and tdTom expressed instead. As expected, in the absence of (re, expression of GFP (green) was were made for cell counts because insufficient numbers of animals were available $(n=3$ mice were used for most anatomical work).

\section{Results}

Sox10-GFP/tdTom dual reporter mice We generated an OL lineage-specific dual reporter mouse line Sox10-lox-eGFP-STOPlox-tdTomato (referred to as Sox10-GFP/tdTom) by PAC transgenesis (Fig. $1 A$ and Materials and Methods). This line was designed to label Sox10-expressing OLPs and differentiated OLs constitutively with enhanced GFP (Zhang et al., 1996) (e.g., Fig. $1 B, E$ ) or conditionally (in the presence of Cre recombinase) with tandem-duplicated Tomato (tdTom) (Shaner et al., 2004). In the absence of Cre, $96 \% \pm 0.2 \%(n=3$ mice) of SOX10-immunoreactive cells also expressed GFP in the corpus callosum at P12/13 (Fig. $1 H$ ). In P10-P13 spinal cord white matter, $86 \pm 4 \%(n=4$ mice $)$ of $\mathrm{SOX}^{+} 0^{+}$cells were $\mathrm{GFP}^{+}$(Fig. $1 H$ ). In both brain and spinal cord, $98 \pm 1 \%$ of $\mathrm{GFP}^{+}$ cells were also SOX $10^{+}$(not shown). In addition, immunolabeling with anti-GFP together with monoclonal antibody CC-1, which labels differentiated OLs (Fig. $1 I-K$ ), or anti-OLIG2, which labels all stages of the OL lineage (Fig. $1 L-N$ ), confirmed that the vast majority of OL lineage cells were labeled by GFP $\left[94.6 \pm 0.7 \%(n=3\right.$ mice $)$ of $\mathrm{CC}^{+}$ cells and $91.9 \pm 1.6 \%$ of OLIG $2{ }^{+}$cells $(n=$ 3 mice) in the corpus callosum between P10 and $\mathrm{P} 13$ were $\left.\mathrm{GFP}^{+}\right]$. As expected, there was no expression of tdTom in brain or spinal cord in the absence of Cre (not shown). In the presence of Cre, the eGFP-STOP cassette was excised and tdTom was expressed instead (see Fig. 2 and below).

Ventrally and dorsally derived OL lineage cells are electrically similar Cortical white matter

We showed previously that NG2-expressing OLPs in the postnatal cerebellar

$\leftarrow$

noted in a majority of SOX10 ${ }^{+}$cells (red) in the forebrain $(\boldsymbol{B}-\boldsymbol{D})$ and spinal cord $(\boldsymbol{E}-\boldsymbol{G})$. Boxed areas in $\boldsymbol{B}$ and $\boldsymbol{E}$ are shown at higher magnification in $\boldsymbol{C}, \boldsymbol{D}$, and $\boldsymbol{F}, \boldsymbol{G}$, respectively. Cell counts at P10 $-\mathrm{P} 13(\boldsymbol{H})$ revealed that $\sim 96 \%$ ( $n=3$ mice) of SOX $10^{+}$cells in the corpus callosum and $\sim 86 \%(n=4$ mice) of SOX10 ${ }^{+}$cells in the spinal cord white matter were GFP (data shown as mean \pm SEM). The vast majority of GFP ${ }^{+}$cells (green) was confirmed to be $0 \mathrm{~L}$ lineage by double immunolabeling spinal cord white matter for $(C-1$, which labels differentiated $0 \mathrm{Ls}$ (red, $\boldsymbol{I}-\boldsymbol{K})$, or anti-0LIG2, which labels all stages of the lineage (red, $\boldsymbol{L}-\boldsymbol{N}$ ). Arrows in $\boldsymbol{I}-\boldsymbol{K}$ indicate $\mathrm{GFP}{ }^{+} \mathrm{OLS}$ that colabel with $\mathrm{CC}-1$; arrowheads indicate $\mathrm{GFP}^{+}, \mathrm{CC}_{-1}-$ negative OLPs. tdTom was not expressed in the absence of $\mathrm{Cre}$ (not shown). Cell nuclei were poststained with Hoechst 33258 (Hst, blue). The images in $\mathbf{I}-\boldsymbol{N}$ were taken in the corpus callosum at P12. Scale bars: $\boldsymbol{D}, \mathbf{G}, 20 \mu \mathrm{m} ; \boldsymbol{K}, \boldsymbol{N}, 25 \mu \mathrm{m}$. 
white matter and corpus callosum fall into two classes-those that express voltagegated $\mathrm{Na}^{+}$channels and receive synaptic input and others that do not (Káradóttir et al., 2008). We also reported that the postnatal corpus callosum is populated by OLPs that migrate from the ventral telencephalon (the forerunner of the forebrain) before birth, intermingled with OLPs that develop locally within the cortex after birth (Kessaris et al., 2006). This raised the possibility that the two electrical subtypes of OLPs might correspond to the two developmental subgroups.

We tested this by patch clamping OLPs in Gsh2-Cre: Sox10-GFP/tdTom doubletransgenic mice. In the telencephalon, Gsh2-Cre is expressed in the lateral ganglionic eminence (LGE) and the dorsal part of the medial ganglionic eminence (MGE) (i.e., the region colored red in Fig. 2A). The ventral MGE (which expresses Nkx2.1 but not Gsh2) makes a negligible contribution to the cortical OL population after P10 (Kessaris et al., 2006). In Gsh2-Cre: Sox10GFP/tdTom mice, OL lineage cells derived from the LGE and dorsal MGE have their GFP coding sequences removed by Cre recombinase and consequently fluoresce red (tdTom), while those from the developing cortex, which do not undergo Cre recombination, fluoresce green (GFP). As expected, the cortical gray and white matter contained intermingled red- and green-labeled cells, reflecting a mixture of ventrally and dorsally derived OL lineage cells (Fig. 2C). In these mice, the red cells are undoubtedly ventral in origin, but green cells could either be genuinely dorsal in origin or else ventrally derived cells that somehow escaped Cre recombination-e.g., because Cre protein is expressed at too low a level to bind the lox recombination sites efficiently. We were able to resolve this uncertainty by crossing Sox10-GFP/tdTom to Emx1-Cre mice, which express Cre (hence activating tdTom expression) in a reciprocal pattern to Gsh2-

Cre, i.e., in the cortical VZ but not in the LGE or MGE (i.e., region colored red in Fig. 2B). Cells that are labeled red by Gsh2-Cre will remain green in Emx1-Cre and vice versa. It follows that the proportion of OL lineage cells that is labeled red by Gsh2-Cre plus the proportion that is labeled red by Emx1-Cre should equal 100\%. We found that $23 \pm 1 \%(n=7$ mice $)$ of OL lineage cells in the P12/13 corpus callosum were recombined red by Gsh2-Cre and $81 \pm 1 \%$ ( $n=5$ mice) by Emx1-Cre (Fig. $2 C-G$ ). Since the sum of these contributions is not significantly different from $100 \%$, we can infer that (1) Cre recombination efficiency is close to $100 \%$ in both Emx1Cre and Gsh2-Cre (i.e., no cells escape the action of Cre) and (2) $\sim 80 \%$ of OL lineage cells in the postnatal corpus callosum are generated locally in the cortical VZ, the remaining $~ 20 \%$ migrating in from the LGE and MGE.

Having determined that our dual reporter system reliably distinguishes ventrally and dorsally derived cells, we made electro-
B Emx1-Cre:Sox10-GFP/tdTom
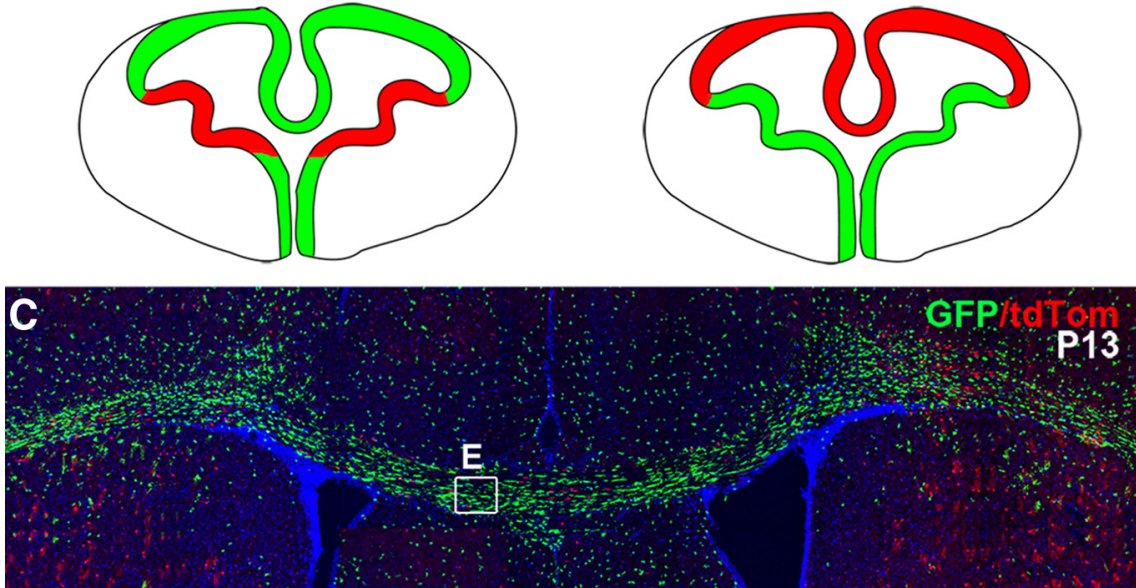

Gsh2-Cre:Sox10-GFP/tdTom

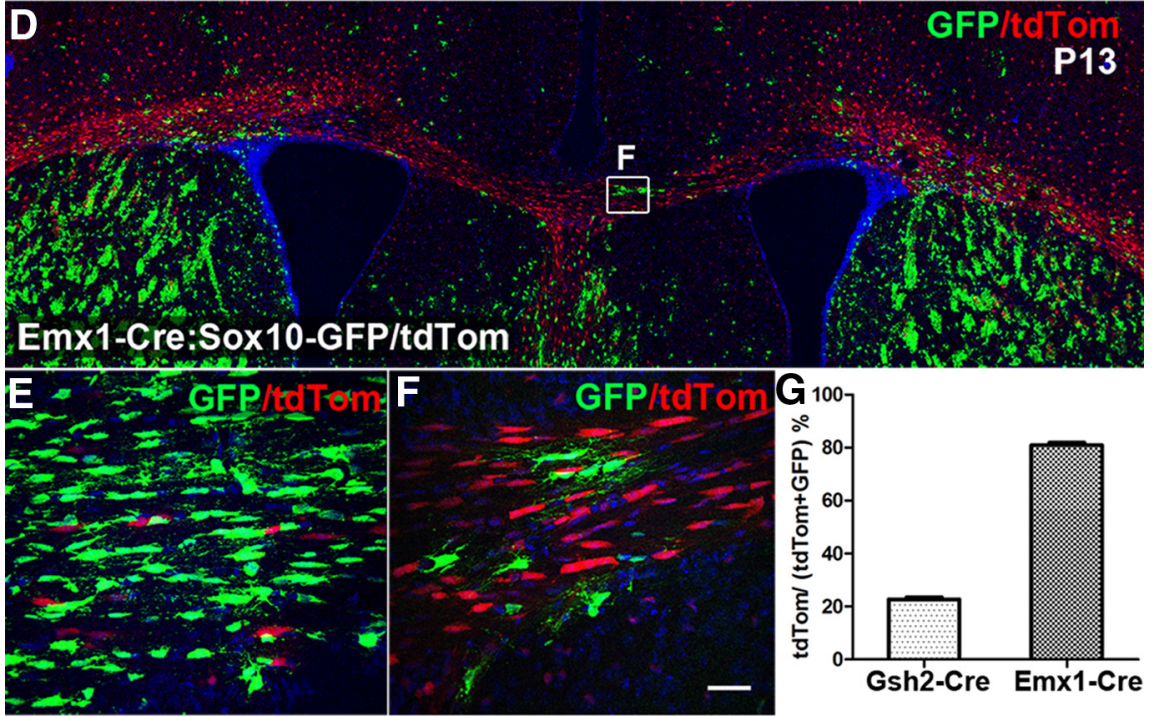

Figure 2. The corpus callosum is populated mainly by dorsally derived OLs. Gsh2 is expressed only in the LGE and dorsal MGE (A, shown in red), whereas Emx 1 is expressed in the developing dorsal telencephalon ( $\boldsymbol{B}$, shown in red). In Gsh2-Cre: Sox10-GFP/tdTom animals, the corpus callosum (CC) was populated mainly by unrecombined (green) 0 L lineage cells $(\boldsymbol{C})$, and consistent with this, in $D$ are shown at higher magnification in $\boldsymbol{E}$ and $\boldsymbol{F}$, respectively. Cell nuclei were poststained with Hoechst 33258 (Hst, blue). G, Cell (he labeled OL population in Gsh2-Cre: Sox10-GFP/tdTom were $\mathrm{dTom}^{+}$, i.e., derived from MGE/LGE, whereas $\sim 80 \%$ ( $n=5$ mice) of labeled cells in the CC of Emx1-Cre: Sox10-GFP/tdTom were $\mathrm{tdTom}^{+}$, i.e., originating in the cortex. Data are presented as mean \pm SEM. Scale bar: $20 \mu \mathrm{m}$.

physiological recordings from dOLPs and vOLPs in acute vibratome slices of Gsh2-Cre: Sox10-GFP/tdTom forebrain at P9P12 (median age P11). Figure $3, A$ and $B$, shows representative images and current traces obtained from vOLPs (tdTomexpressing, red) and dOLPs (eGFP-expressing, green). Before recording, the cells were identified by their expression of red or green fluorescence (Fig. 3A, B, top images). They were then whole-cell clamped using an internal solution containing a green or red dye (for the red and green cells, respectively: Fig. 3A, $B$, middle images), allowing colocalization of the fluorescent reporter protein and the pipette dye to demonstrate that the correct cell had been patch clamped (Fig. $3 A, B$, bottom images). On applying $20 \mathrm{mV}$ voltage steps from a holding potential of -70 $\mathrm{mV}$ (Fig. $3 A, B$, top traces), depolarization was seen to evoke a transient inward $\left(\mathrm{Na}^{+}\right)$current in the majority of cells, followed by a more sustained outward $\left(\mathrm{K}^{+}\right)$current (Káradóttir et al., 


\section{Corpus callosum}
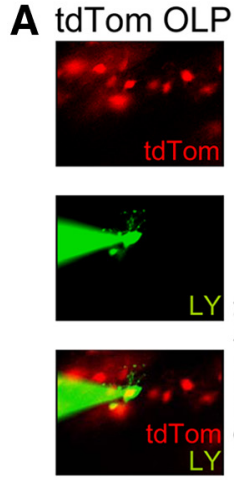
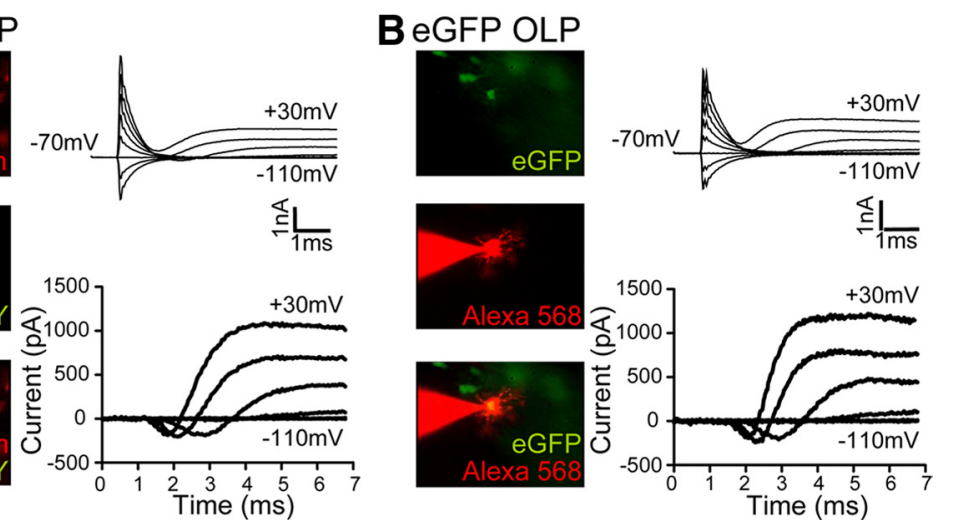
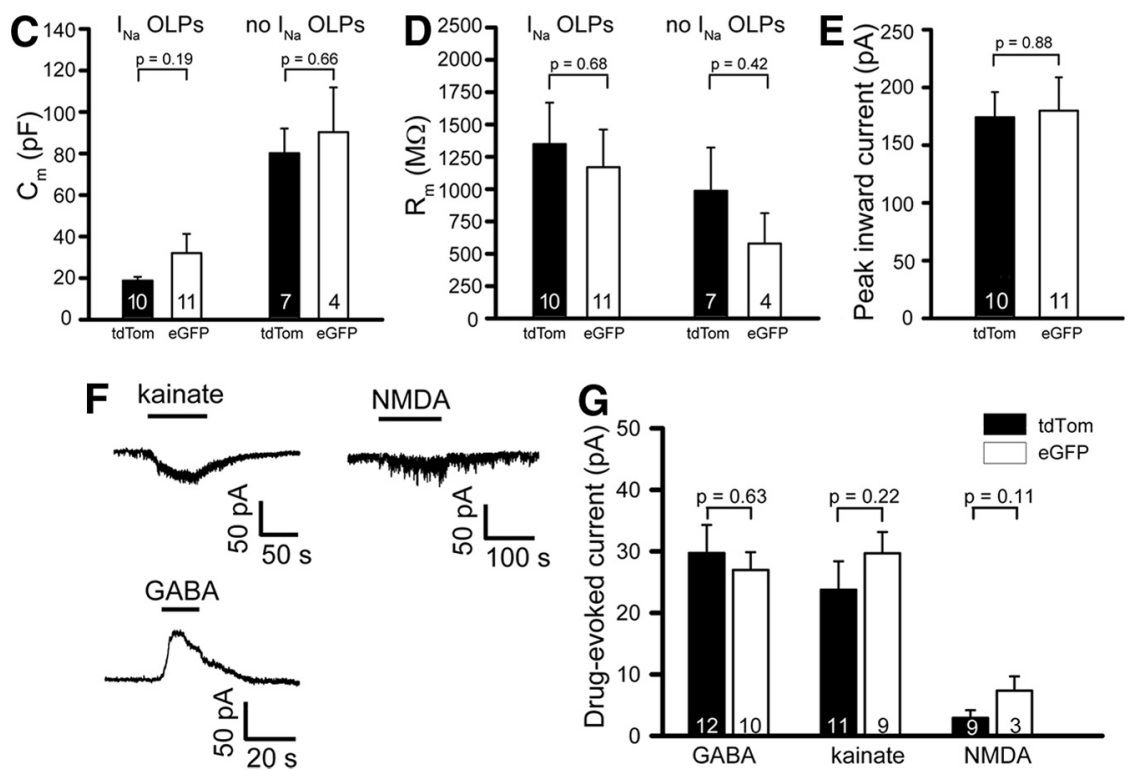

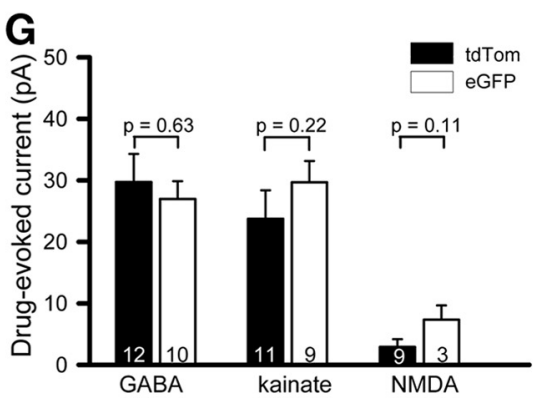

Figure 3. Electrophysiological properties of ventrally and dorsally derived OLPs in the corpus callosum. $A$, A v0LP expressing tdTom under Sox 10 transcriptional control (in Gsh2-Cre: Sox10-GFP/tdTom mice; top) was whole-cell clamped with an internal solution containing Lucifer yellow (green: middle). Bottom panel shows overlay. Top current traces are in response to $20 \mathrm{mV}$ steps from $-70 \mathrm{mV}$. Bottom traces are after subtraction of the linearly scaled response to the step to $-110 \mathrm{mV}$. $B$, As in $A$ but for a dOLP expressing eGFP under Sox 10 control (in Gsh2-Cre:Sox10-GFP/tdTom mice). C, D, Comparison for v0LPs (tdTom) and dOLPs (eGFP), with and without $\mathrm{Na}^{+}$current, of membrane capacitance $(\boldsymbol{C})$ and membrane resistance $(\boldsymbol{D})$ at $-70 \mathrm{mV}$. $\boldsymbol{E}$, Comparison of peak net inward current evoked in $I_{\mathrm{Na}}$-expressing $0 \mathrm{LPs}$ by a step from $-70 \mathrm{mV}$ to $+10 \mathrm{mV}$. F, Specimen responses of an $0 \mathrm{LP}$ to kainate (100 $\mu \mathrm{M})$ and NMDA $(60 \mu \mathrm{M})$ at $-70 \mathrm{mV}$ and to $\mathrm{GABA}(100 \mu \mathrm{M})$ at $-40 \mathrm{mV}$. G, Magnitude of drug-evoked currents (as in $\boldsymbol{E})$ for v0LPs and dOLPs expressing $I_{\mathrm{Na}}$.

2008; L. E. Clarke, K. M. Young, N. B. Hamilton, W. D. Richardson, D. Attwell, unpublished work). Subtraction of the linearly scaled capacity transient and (ohmic) current evoked by hyperpolarizing steps revealed a clear transient inward $\mathrm{Na}^{+}$current $\left(I_{\mathrm{Na}}\right)$ that partly overlapped with the onset of the $\mathrm{K}^{+}$current (Fig. $3 A, B$, bottom traces). As previously reported (Káradóttir et al., 2008), $\sim 35 \%$ of fluorescing cells with OLP morphology lacked detectable $\mathrm{Na}^{+}$current, but the presence or absence of $I_{\mathrm{Na}}$ did not correlate with the developmental origin of the cells ( 10 of $17 \mathrm{vOLPs}$ and 11 of 15 dOLPs displayed $\mathrm{Na}^{+}$currents; not significantly different, $p=0.63$ ). Some of the $I_{\mathrm{Na}}$-negative cells presumably were OLPs that were differentiating into mature OLs (De Biase et al., 2010; Kukley et al., 2010), while others were NG2-expressing OLPs that lacked significant $\mathrm{Na}^{+}$current (Clarke et al., 2011).

The capacitance of OLPs (Fig. 3C), their membrane resistance near the resting potential (Fig. $3 D$ ), and the net inward current that $I_{\mathrm{Na}}$-expressing OLPs generated on depolarization from $-70 \mathrm{mV}$ to $+10 \mathrm{mV}$ (Fig. 3E) did not differ significantly between dOLPs and vOLPs. Similarly, the responses of $I_{\mathrm{Na}}$-expressing OLPs to neurotransmitter application did not differ significantly. Kainate and NMDA evoked inward currents at $-70 \mathrm{mV}$, while GABA evoked an outward current at $-40 \mathrm{mV}$ (Fig. $3 F$ ) but the amplitudes of these currents were indistinguishable between the OLPs of different origin (Fig. 3G). Thus, although we confirmed the existence of two electrical subtypes of cell with OLP morphology in the subcortical white matter and corpus callosum, we determined that these do not correspond to dOLPs versus vOLPs.

Similarly, the electrical properties of mature myelinating OLs derived from the ventral VZ (tdTom-expressing, red) (Fig. $4 A$ ) or dorsal VZ (eGFP-expressing, green) (Fig. 4B) did not differ significantly. Their current response to voltage steps was approximately ohmic with slight outward rectification (Fig. $4 A, B$ ), with an input resistance at $-70 \mathrm{mV}$ that was not significantly different between dOLs and vOLs (Fig. 4C). dOLs and vOLs were found to myelinate a similar range of numbers of internodes (between 2 and 21, the distribution of which did not differ significantly: $p=0.45$ comparing dOLs and vOLs) (Fig. $4 D$ ). Accordingly, the mean number of internodes was not different for dOLs and vOLs $(p=0.2)$ (Fig. $4 E)$. Their responses to kainate and NMDA were also not significantly different from one another (Fig. $4 F, G$ ).

\section{Spinal cord white matter}

The VZ of the developing spinal cord is composed of a series of discrete progenitor domains known as $\mathrm{p} 3, \mathrm{pMN}, \mathrm{p} 2, \mathrm{p} 1$, and $\mathrm{p} 0$ in the ventral half of the cord and dP6 to dP1 in the dorsal half (reading ventral to dorsal) (Fig. 5A). Each progenitor domain generates a characteristic subset of spinal neurons before switching to production of glial cells (astrocytes and/or OLPs). Most OLPs in the spinal cord are generated from the pMN domain in the ventral VZ, but a minority are generated outside pMN, mainly from the dorsal VZ (Cai et al., 2005; Fogarty et al., 2005; Vallstedt et al., 2005).

We specifically marked dOLPs and their differentiated dOL progeny by crossing Sox10-GFP/tdTom with Msx3-Cre, which is expressed in progenitor domains $\mathrm{dP} 1-\mathrm{dP} 5$, or Gsh2-Cre, which is expressed in dP3-dP5 (Fig. 5A). In P12/13 double-transgenic animals, Gsh2-derived cells were $10 \pm 2 \%(n=3$ mice $)$ of all OL lineage cells in the cord, whereas Msx3-derived cells were $17 \pm$ $1 \%(n=5$ mice $)$ of the total. This is in keeping with the broader expression domain of $M s x 3$ and indicates that $\mathrm{dP} 1$ and/or $\mathrm{dP} 2$ give rise to some OL lineage cells in addition to dP3-dP5. Thereafter, Msx3-Cre was used to label dorsally derived OLPs and OLs 
in the spinal cord. Msx3-derived OL lineage cells (red) were concentrated in the dorsal and dorsolateral funiculi (Fig. $5 B, C$ ), whereas vOLPs (green) were distributed widely throughout the cross section of the cord (Fig. 5B). This confirms previous reports that dOLPs are less migratory than their vOLP counterparts. This could either be an intrinsic difference or reflect the fact that dOLPs appear late-after vOLPs have already colonized the cord - and are outcompeted by vOLPs for migration- or proliferation-inducing factors (e.g., platelet-derived growth factor, PDGF). Consistent with the latter idea, dOLPs proliferate and migrate more than normal when vOLs are absent in Nkx6.1/Nkx6.2 double-null mice (Cai et al., 2005; Vallstedt et al., 2005) and when the PDGF supply is increased experimentally (Calver et al., 1998; van Heyningen et al., 2001).

We recorded from red (tdTom-expressing, dorsally derived) and green (GFPexpressing, ventrally derived) OL lineage cells in the dorsal and dorsolateral funiculi of the P6-P14 spinal cord (median age P8). Patch-clamped cells were identified as OLPs and mature OLs from their morphology and membrane current properties, as described previously for recordings in brain slices. Spinal cord OLP-morphology cells, like those in brain, fell into two classes, either with or without $\mathrm{Na}^{+}$currents, and the mean capacitance of the cells without $I_{\mathrm{Na}}$ was larger (Fig. $5 D$ ). The membrane resistance of dOLPs and vOLPs with $I_{\mathrm{Na}}$ was not significantly different (Fig. 5E), and this was also true for dorsally and ventrally derived mature OLs. However, the resistance of vOLPs without $I_{\mathrm{Na}}$ was larger than that for dOLPs. This was the only electrophysiological difference we found between dOLPs and vOLPs, but would become insignificant if correction were made for multiple comparisons. The presence or absence of $I_{\mathrm{Na}}$ did not correlate with the developmental origin of the cells, because dOLPs and vOLPs were both found either with or without $I_{\mathrm{Na}}(10$ of $16 \mathrm{dOLPs}$ and 10 of $16 \mathrm{vOLPs}$ expressed $I_{\mathrm{Na}}$ ). In $I_{\mathrm{Na}}$-expressing cells, the peak inward current (evoked by a step from $-70 \mathrm{mV}$ to $+10 \mathrm{mV}$ ) was not significantly different between the two groups (Fig. $5 F$ ). Dorsally and ventrally derived mature OLs myelinated a similar range of number of internodes (between 2 and 6 , the distribution of which did not differ significantly: $p=0.21 \mathrm{com}-$ paring dOLs and vOLs) (Fig. 5G). Consequently, the mean number of internodes did not differ significantly between dOLs and $\operatorname{vOLs}(p=0.23)(\mathrm{Fig} .5 H)$. There were no significant differences between dOLPs and vOLPs with $I_{\mathrm{Na}}$ in their responses to $100 \mu \mathrm{M}$ GABA (at $-40 \mathrm{mV}$ ) or to $100 \mu \mathrm{M}$ kainate or $60 \mu \mathrm{M}$ NMDA (at $-70 \mathrm{mV}$ ) (Fig. 5I), nor between dOLs and vOLs in their responses to kainate and NMDA (Fig. $5 J$ ).

\section{Corpus callosum}
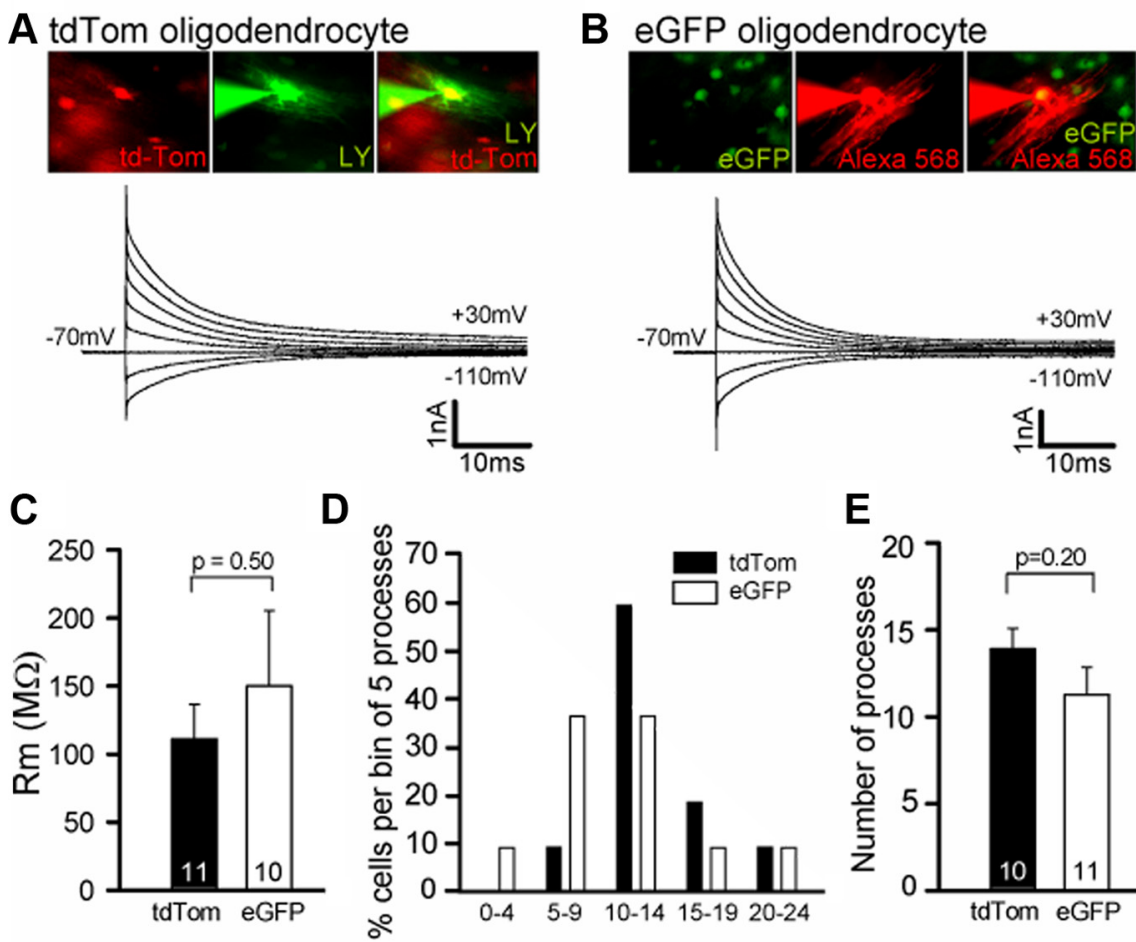

E

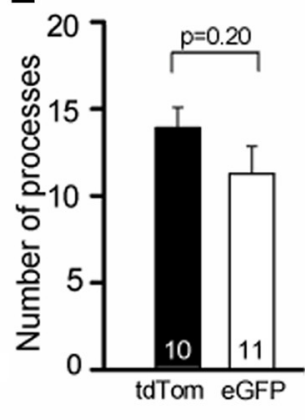

$\mathbf{G}$

Figure 4. Comparison of the electrical properties of ventrally and dorsally derived mature OLs (vOLs and dOLs) in the forebrain A, A v0 L expressing tdTom in Gsh2-Cre: Sox10-GFP/tdTom mice (left) was whole-cell clamped with an internal solution containing $\mathrm{mV}$ steps from $-70 \mathrm{mV}$. $\boldsymbol{B}$, As in $\boldsymbol{A}$ but for a d0L expressing eGFP in Gsh2-Cre: Sox10-GFP/tdTom mice; thin red processes are internodes. C, Comparison for v0Ls (tdTom) and d0Ls (eGFP) of membrane resistance at $-70 \mathrm{mV}$. D, Percentage of v0Ls (tdTom) processes made by v0Ls and d0Ls. $\boldsymbol{F}$, Specimen responses of an $0 \mathrm{~L}$ to kainate (100 $\mu \mathrm{m})$ and NMDA (60 $\mu \mathrm{m})$ at $-70 \mathrm{mV}$. $\boldsymbol{G}$, Magnitude of drug-evoked currents (as in $\boldsymbol{F}$ ) for v0Ls and d0Ls.

\section{Corticospinal and rubrospinal tracts are myelinated mainly} by dorsally derived OLs

At P7, the most ventral part (base) of the dorsal columns-where the developing CSTs run-was devoid of dOLPs/dOLs and contained few vOLPs/vOLs compared to other regions of developing white matter (Fig. 6A, $A^{\prime}, E, E^{\prime}$ ). This could be because most corticospinal projections have not yet reached the spinal cord; the first corticospinal axons reach lumbar (L5) spinal cord at P6-P9, and the CST does not achieve its full size until $\sim$ P14 (Gianino et al., 1999; Bareyre et al., 2005). It makes sense that OL lineage cells should be excluded from the paths of growing axons, since myelin components (several of which are expressed at a low level on OLPs) are known to be inhibitory for axon outgrowth. Since neither the CST nor the RSTs could be specifically labeled at this 

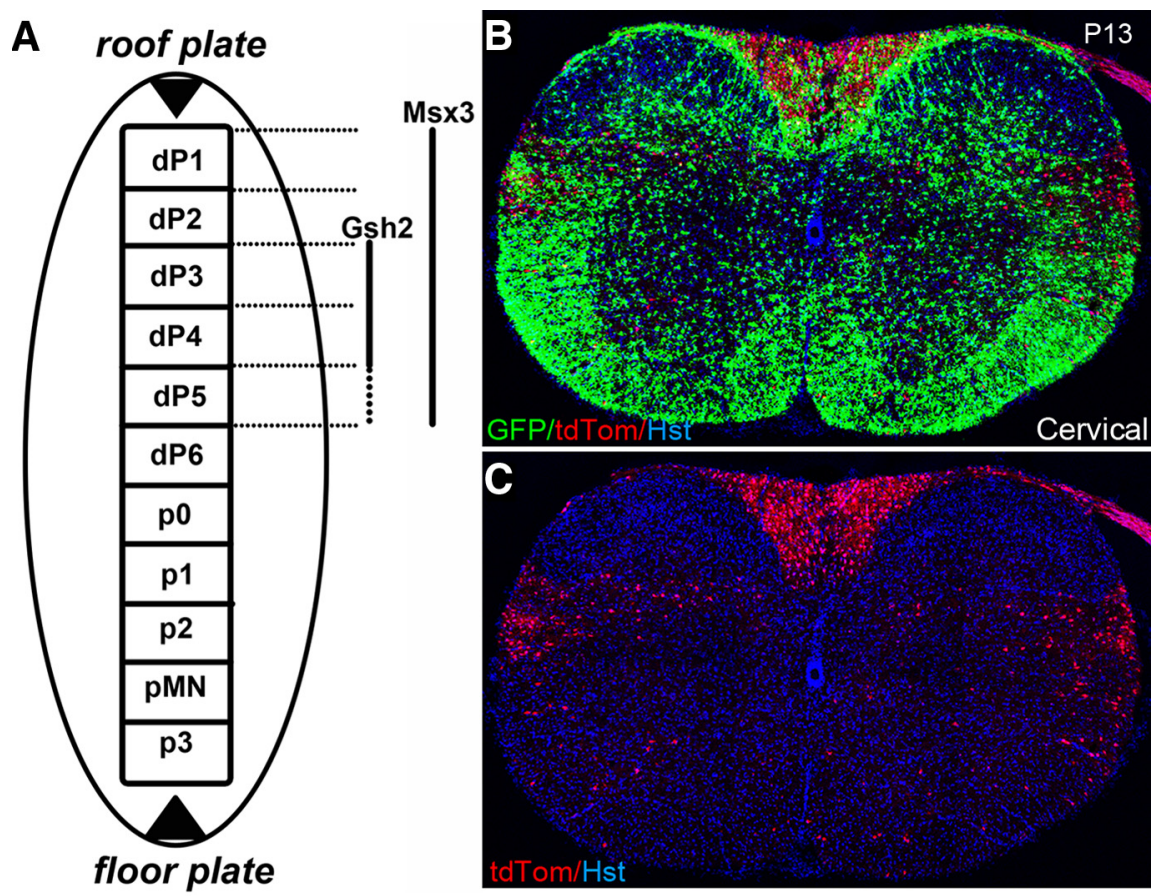

D

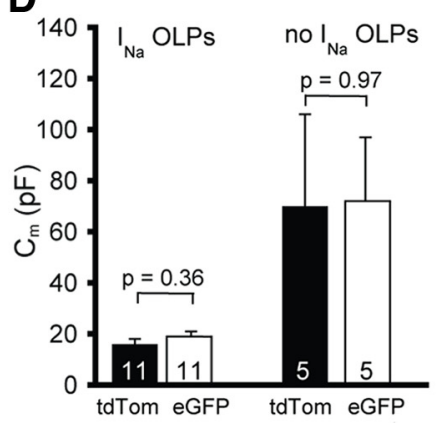

E
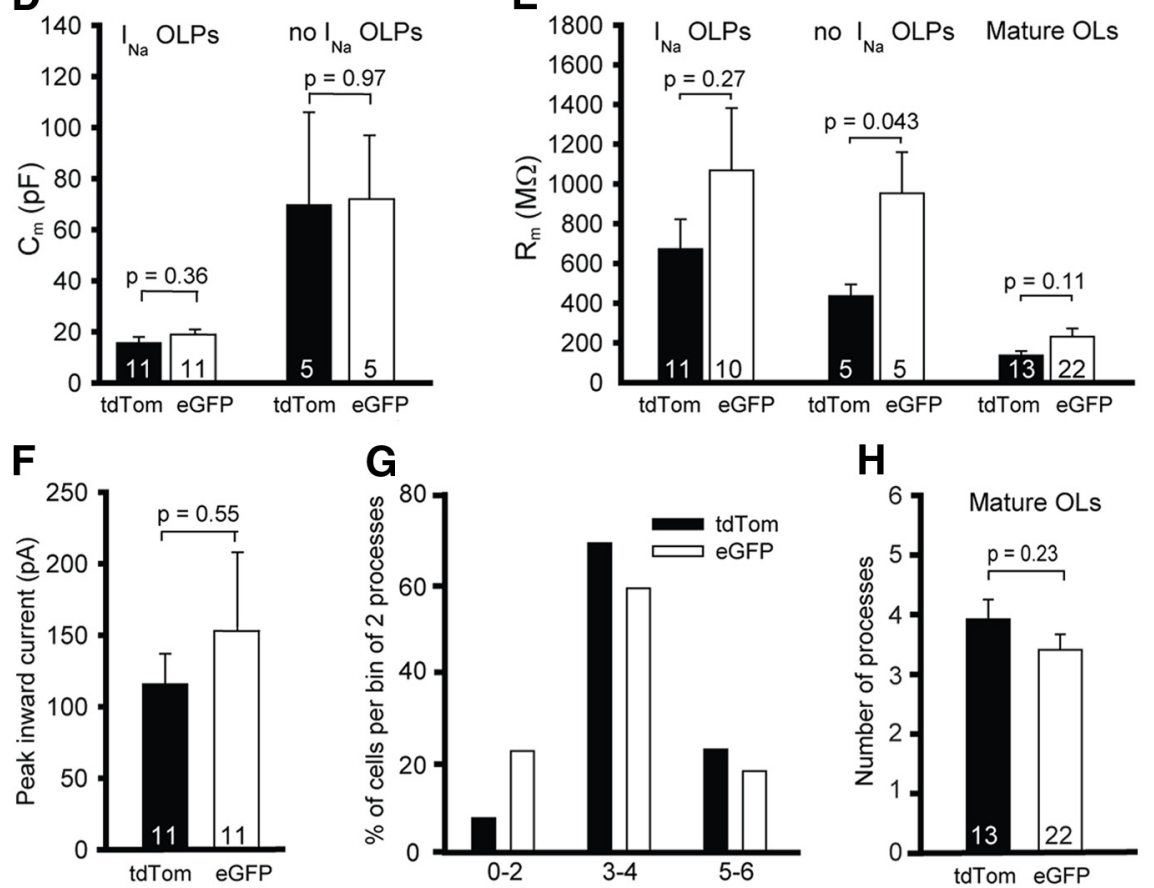

G
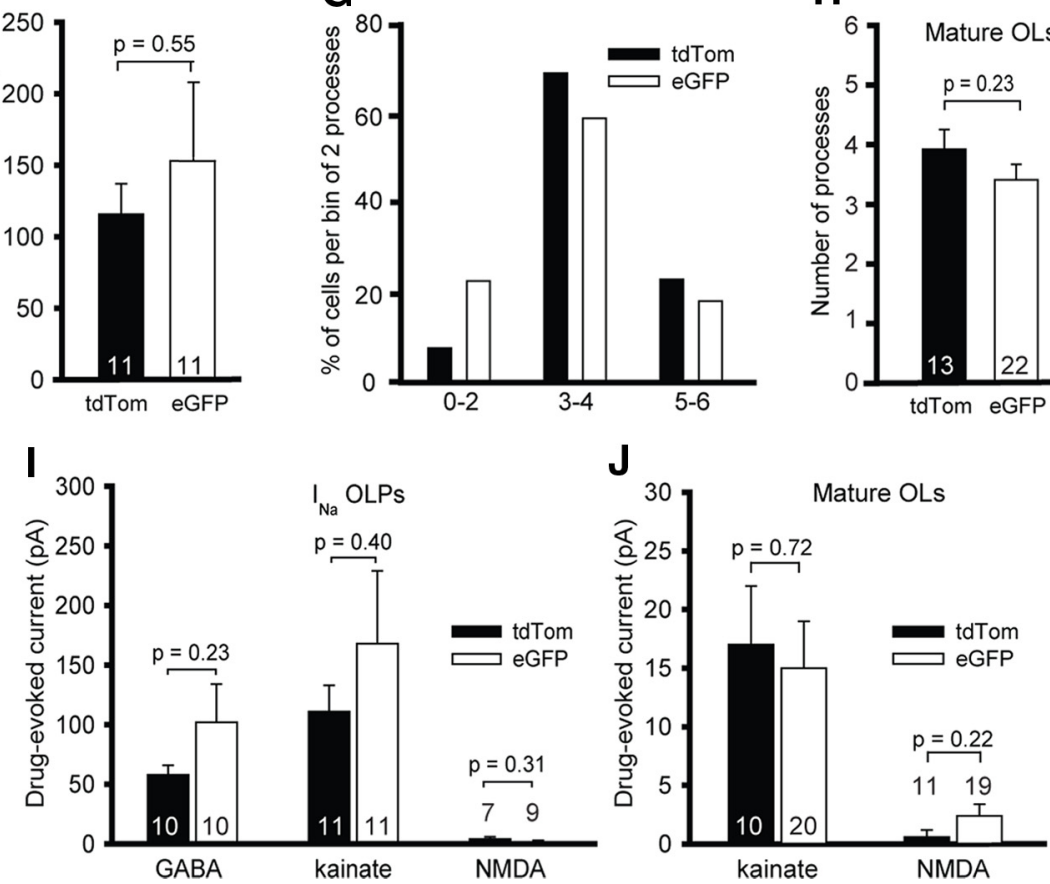

Figure 5. Dorsally and ventrally derived $0 \mathrm{~L}$ lineage cells in the spinal cord have similar electrical properties. $\boldsymbol{A}-\boldsymbol{C}, \mathbf{O}$ rigin and location of spinal dOLPs and vOLPs. $\boldsymbol{A}$, In the developing spinal cord Msx3 is expressed in dorsal domains $\mathrm{dP} 1-\mathrm{dP5}$, whereas Gsh 2

$\mathrm{H}$

early age, we referred to an anatomical atlas (Watson et al., 2008) to locate these tracts at $\mathrm{P} 7$ and $\mathrm{P} 13$. At P7, there were only a few ventrally derived OL lineage cells in the CST and even fewer dorsally derived cells (Fig. 6A, $A^{\prime}, E, E^{\prime}$ ). At cervical levels, for example, only $\sim 8 \%$ of $\mathrm{OL}$ lineage cells in the CST were dorsally derived, the remaining $\sim 92 \%$ being ventrally derived (Fig. 6C). By P13, there were many OL lineage cells in the CST, still mainly ventrally derived although the dorsal contribution had also increased (Fig. 6B, $B^{\prime}, C, F, F^{\prime}$ ). In the cervical CST, for example, the dorsal contribution had increased from $\sim 8 \%$ to $\sim 34 \%$ (Fig. $6 C$ ). In neighboring dorsal tracts, such as the fasciculus gracilis and fasciculus cuneatus (which are ascending sensory tracts), the opposite was true-at cervical level, $\sim 63 \%$ of labeled cells in these tracts were dorsally derived at P13 (Fig. 6D). The RSTs in the dorsolateral funiculi were equally populated by dorsally and ventrally derived OL lineage cells at P13 (50 \pm $2 \%$ were dorsally derived, $n=3$ mice). At this stage, only a minor proportion of labeled OL lineage cells in the ventral funiculus was dorsally derived ( $10 \pm 3 \%, n=3$ mice).

These observations suggested that there were some tract preferences of dorsally and ventrally derived OLs. To see whether this persisted long-term, we examined adult Msx3-Cre: Sox10-GFP/tdTom spinal cords. Unexpectedly, we found that the dorsal funiculus, especially

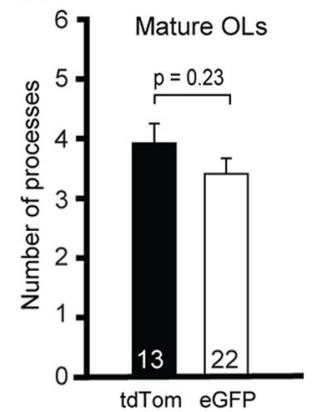

is expressed only in $\mathrm{dP3}-\mathrm{dP5}$. Hence, Msx3-Cre: Sox10-GFP/ tdTom was used to examine dorsally derived $0 \mathrm{~L}$ lineage cells in the spinal cord. B, C, At P13, ventrally derived OLPs and OLs (green) are evenly spread throughout the spinal cord $(\boldsymbol{B})$, whereas dorsally derived $0 \mathrm{~L}$ lineage cells (red) are mainly restricted to the dorsal and dorsolateral regions of the cord $(\boldsymbol{C})$ (images are of cervical cord; see also Fig. 6H). Very few dorsally derived cells were observed in the ventral funiculus. Note that the dorsal funiculus is dominated by dorsally derived (red) cells except for the ventralmost part (CSTs), where ventrally derived (green) cells are more abundant. In contrast, in the dorsolateral funiculus, where the RSTs run, there appears to be an accumulation of dorsally derived cells. Cell nuclei were poststained with Hoechst 33258 (Hst, blue). D-I, Electrical properties of spinal dorsally and ventrally derived $\mathrm{OL}$ lineage cells. $\boldsymbol{D}$, Membrane capacitance of dorsal (tdTom-expressing) and ventral (eGFP-expressing) OLP morphology cells. $\boldsymbol{E}$, Membrane resistance at $-70 \mathrm{mV}$ of $0 \mathrm{LP}$ morphology cells with and without $I_{\mathrm{Na}}$ and of mature $0 \mathrm{LS}$. $\boldsymbol{F}$, Peak inward current evoked by depolarization from $-70 \mathrm{mV}$ to $+10 \mathrm{mV}$ in $0 \mathrm{LPs}$ with $I_{\mathrm{Na}}$. $G$, Percentage of dOLs and v0Ls with different numbers of internodal processes ( $13 \mathrm{~d} 0 \mathrm{Ls}$ and $22 \mathrm{v} 0 \mathrm{Ls}$ were studied). $\boldsymbol{H}$, Mean number of internodal processes made by $\mathrm{d} 0 \mathrm{Ls}$ and $\mathrm{V} 0 \mathrm{Ls}$. $I$, Drug-evoked currents in OLPs with $I_{\mathrm{Na}}$. J, Drug-evoked currents in mature $0 \mathrm{Ls}$ 
the CST, was populated predominantly by dorsally derived OLs at P67 (Fig. 6G, $G^{\prime}$ ), the reverse of the situation at $\mathrm{P} 7$ and $\mathrm{P} 13$ (Fig. 6A-F'). (The locations of tracts are shown in Fig. $6 H$.) This suggests that the dorsal OL lineage displaces the ventral lineage between P13 and P67.

If the absolute number of vOLs in the dorsal funiculus did not change between $\mathrm{P} 13$ and P67, the number of vOLs per section would be expected to decrease $\sim 1.5$ fold because the length of the spinal cord increases $\sim 1.5$-fold during this time with a concomitant increase in volume (see Materials and Methods; since we counted cells in the whole area of the dorsal funiculus-i.e., a larger area at P67 than at P13 - growth in the radial plane is automatically taken into account). However, we found that the number of vOLs per section across the whole area of the dorsal funiculus at cervical level decreased 3.8fold between P13 and P67 (from $110 \pm 9$ to $29 \pm 4, n=3$ mice) (Fig. $6 I$ ), which cannot be explained simply by the increased length of the cord-the absolute number of vOLs must have decreased $\sim 2.5$-fold (i.e., 3.8/1.5). The number of dOLs per section remained steady from P13 to P67 (156 \pm 17 and $163 \pm 26$, respectively, $n=3$ mice) (Fig. $6 I$ ). Because of the increased length of the cord, the absolute number of dOLs must have increased $\sim 1$.5-fold during this period. Therefore, the number of dOLs rises as the number of vOLs falls, suggesting that vOLs are replaced by dOLs. However, it is not simply a matter of one-to-one replacement because the total number of vOLs plus dOLs decreased modestly from P13 to $\mathrm{P} 67$ (from $\sim 266$ to $\sim 192$ per section).

To confirm the location of the CST, we injected the anterograde tracer BDA into the right primary motor cortex of $\mathrm{P} 67$ mice and examined the spinal cord $12 \mathrm{~d}$ later (see Materials and Methods). In 3 of 3 injected animals, the CST was labeled unilaterally on the left. Within the BDAlabeled profile, the majority of OL lineage cells were dorsal in origin (red) at all rostrocaudal levels (Fig. 7A-C). For example, $88 \pm 3 \%(n=3$ mice $)$ of labeled OL lineage cells in the cervical CST were dorsally derived (Fig. 6C). We attempted to label the RSTs by unilateral BDA injection into the red nucleus in the midbrain. This was less reproducible-only 2 of 7 injected mice had any RST labeling. Using this BDA labeling as a guide, we counted cells in the region of the RST and found that they were populated mostly by dorsally derived OLs ( $79 \pm 5 \%, n=3$ mice; not shown). In contrast, ventral and ventrolat-
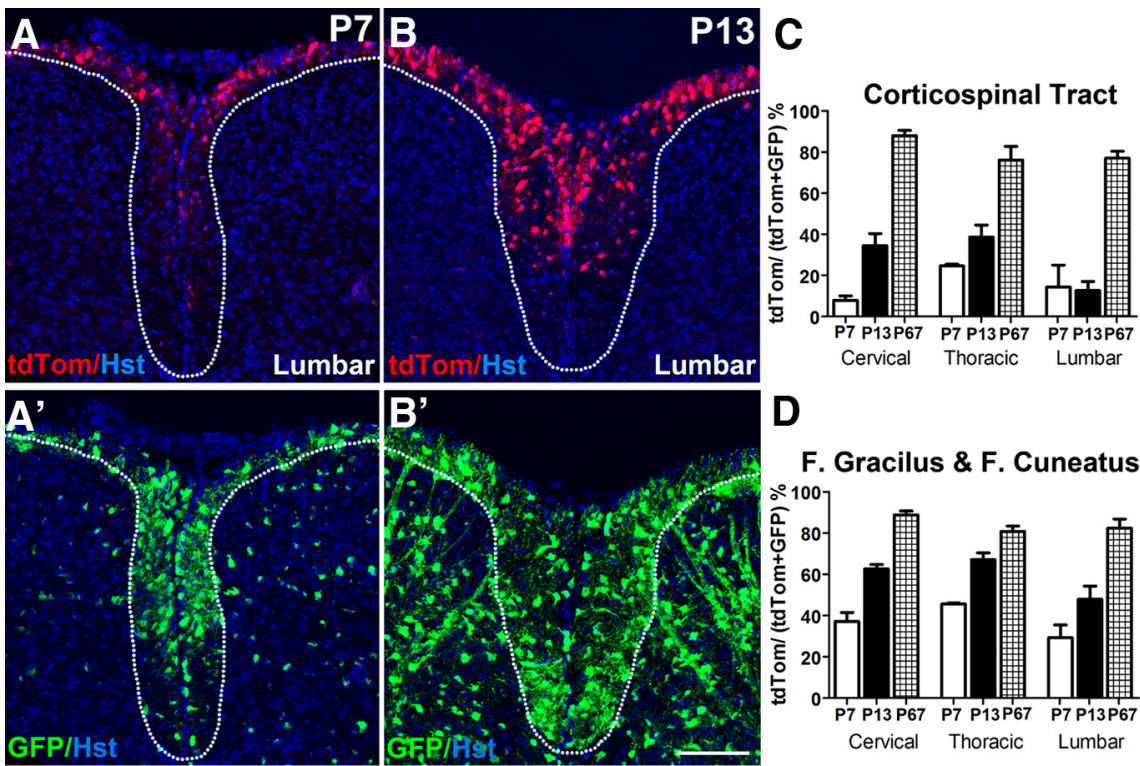

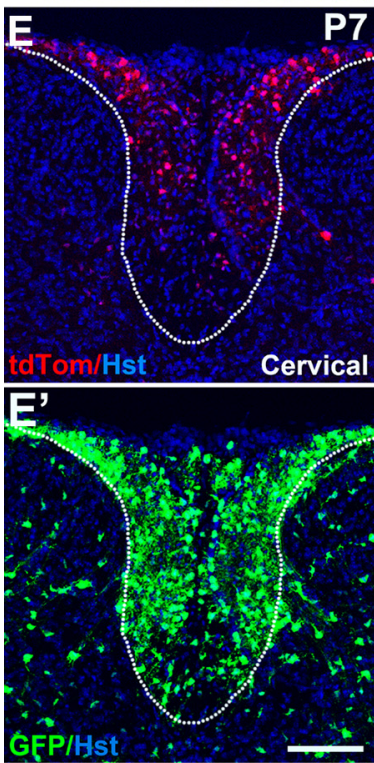

H

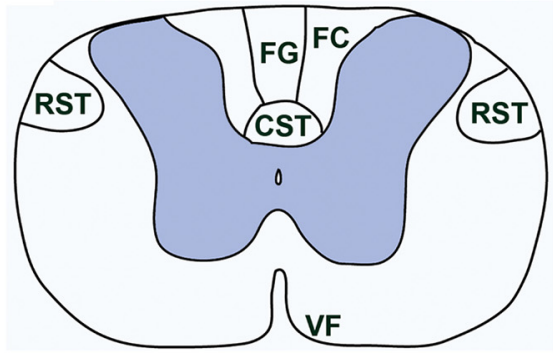

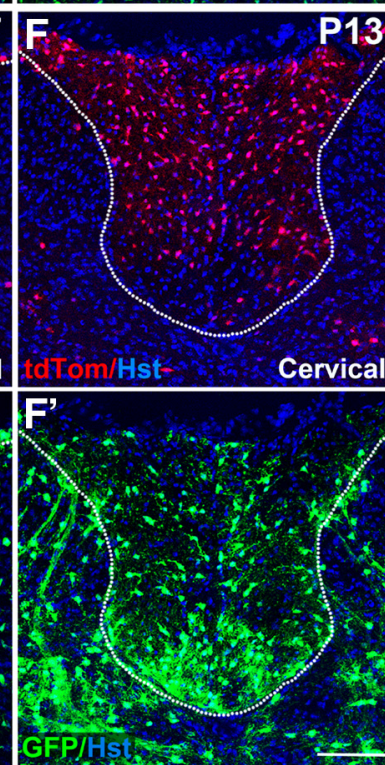

I
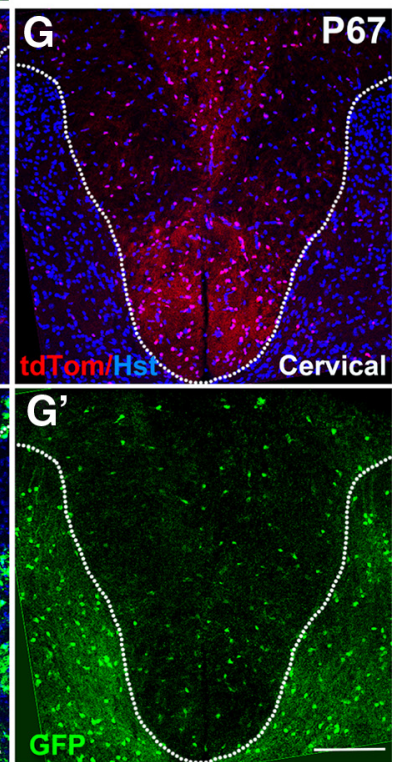

Dorsal Funiculus

(Cervical)

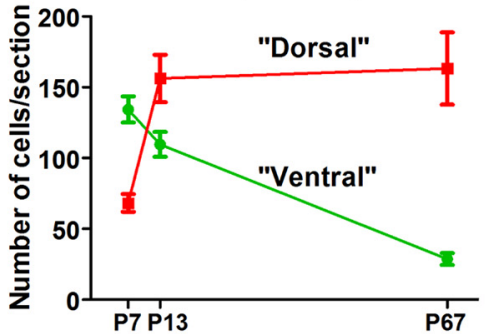

Figure 6. The corticospinal tract is populated mainly by dorsally derived $0 \mathrm{~L}$ lineage cells in adulthood. $\boldsymbol{A}, \boldsymbol{A}^{\prime}$, There are very few $0 \mathrm{~L}$ lineage cells in the CST at P7 in the lumbar cord, and almost none of these are dorsally derived (red). $\boldsymbol{B}, \boldsymbol{B}^{\prime}$, At P13, the CST at lumbar level still has very few dorsally derived $\mathrm{OL}$ lineage cells $(\mathrm{red})(\boldsymbol{B})$, but contains many more ventrally derived (green) cells $\left(\boldsymbol{B}^{\prime}\right)$. This situation reverses by $\mathrm{P} 67$, when the entire dorsal funiculus (DF), especially the CST, is populated mainly by dorsally derived OLPs and $0 \mathrm{Ls}$ as revealed by cell counts $(\boldsymbol{C}, \boldsymbol{D})$. The situation at thoracic and cervical spinal levels is very similar. $\boldsymbol{E}, \boldsymbol{E}^{\prime}, A t P 7$, a majority of cells in the DF and especially the CST are ventrally derived (green). By P13, the numbers of dorsally derived (red) cells increases in the DF (F), but the CST is still mainly populated by dorsally derived cells (green, $\boldsymbol{F}^{\prime}$ ). The proportions of tdTom ${ }^{+}$(dorsally derived) cells in the CST, fasciculus gracilis, and fasciculus cuneatus increase steadily from P7 to adulthood at all spinal levels $(\boldsymbol{C}, \boldsymbol{D})$. Three sections per spinal level were counted for each animal: P7 ( $n=2$ mice) $\left(\boldsymbol{E}, \boldsymbol{E}^{\prime}\right), \mathrm{P} 13(n=3)\left(\boldsymbol{F}, \boldsymbol{F}^{\prime}\right)$, and P67 $(n=3)\left(\boldsymbol{G}, \boldsymbol{G}^{\prime}\right)$. $\boldsymbol{H}$, Drawing of the adult spinal cord showing the tracts and regions examined (VF, ventral funiculus). $I$, The absolute numbers of GFP ${ }^{+}$(ventrally derived) cells/section in the dorsal funiculus (cervical level) decrease dramatically between P7 and P67, while tdTom ${ }^{+}$(dorsally derived) cells increase in number during the same time frame. The images in $\boldsymbol{A}$ and $\boldsymbol{B}$ are of the lumbar spinal cord; all other images are of the cervical cord. Scale bars, $100 \mu \mathrm{m}$. 

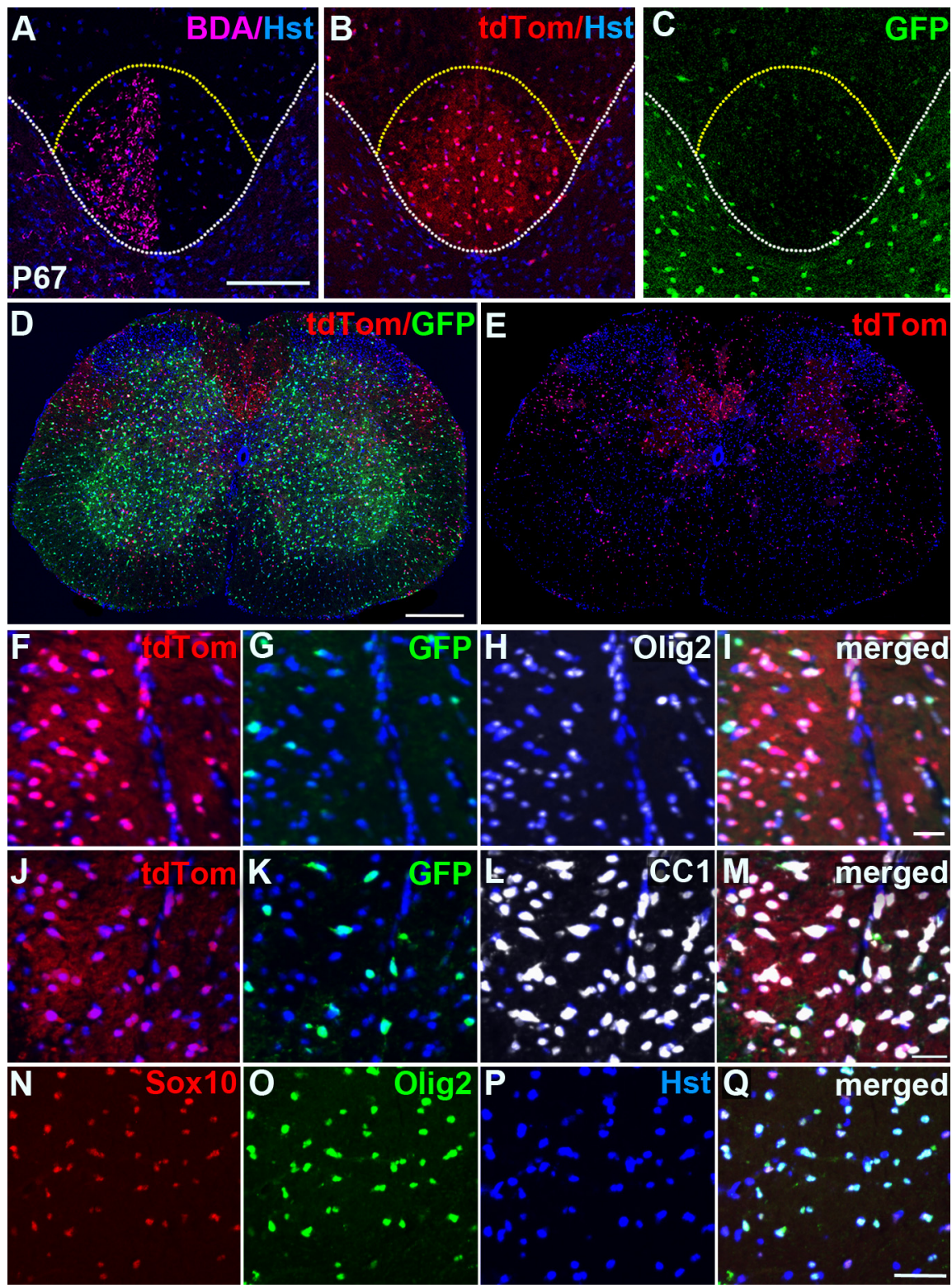

Figure 7. The Sox10-GFP/tdTom reporter faithfully identifies $0 \mathrm{~L}$ lineage cells in the adult. A-C, BDA labeling confirmed that the majority of presumptive $\mathrm{OL}$ lineage cells in the adult $\mathrm{CST}$ are of dorsal origin (tdTom ${ }^{+}$). The white dotted line separates gray matter from white matter and the yellow dotted line outlines the CST. D,E, A cross-sectional image of an adult Msx3-Cre:Sox10-GFP/tdTom spinal cord shows that the dorsal funiculus (especially the CST) and dorsolateral funiculi (RST) contain mainly dorsally derived $\mathrm{tdTom}^{+}$cells. tdTom ${ }^{+}\left(\boldsymbol{F}\right.$, red) and GFP ${ }^{+}\left(\boldsymbol{G}\right.$, green) cells together account for the great majority of $0 \mathrm{LIG2}{ }^{+}$cells $(\boldsymbol{H}-\boldsymbol{I})$ in the adult spinal white matter. In addition, most $C\left(-1^{+}\right.$differentiated $0 \mathrm{Ls}(\boldsymbol{L}-\boldsymbol{M})$ colabeled for either tdTom (red, $\left.\boldsymbol{J}\right)$ or GFP (green, $\left.\boldsymbol{K}\right)$, confirming that the Sox10-GFP/tdTom reporter faithfully identifies OL lineage cells in the adult cord and also that we did not "lose" a significant number of $0 \mathrm{~L}$ lineage cells in adulthood because of reduced GFP or tdTom expression. Almost all SOX10 ${ }^{+}$cells (red, $\boldsymbol{N}$ ) also colabel for 0 LIG2 (green, $\mathbf{0 - Q}$ ) and vice versa in the adult spinal cord. Cell nuclei were poststained with Hoechst 33258 (Hst, blue). All images were taken from the cervical spinal cord. The images in $\boldsymbol{F}-\boldsymbol{Q}$ were taken within the CST. Scale bars: $A, 100 \mu \mathrm{m} ; \boldsymbol{D}$, $250 \mu \mathrm{m} ; \mathbf{I}, \mathbf{M}, 25 \mu \mathrm{m} ; \mathbf{Q}, 35 \mu \mathrm{m}$

eral tracts were occupied mainly by ventrally derived OLPs and OLs, as expected (Figs. $5 B, C, 7 D, E$ ), although the proportion of dorsally derived cells increased with age, from $10 \pm 3 \%(n=3$ mice $)$ at P13 to $24 \pm 4 \%(n=3$ mice $)$ at $\mathrm{P} 67$.

At P67, the GFP and tdTom signal intensities in individual cells were reduced relative to $\mathrm{P} 13$ and the labeled cell profiles were smaller, both effects being more pronounced in white matter compared to gray matter and more obvious for GFP than tdTom. The sum of GFP ${ }^{+}$and tdTom ${ }^{+}$cell counts in the dorsal funiculus at P67 amounted to $80 \pm 5 \%(n=3$ mice $)$ of all SOX10- immunoreactive cells in the dorsal funiculus, which is not significantly different $(p=0.22)$ from the number of SOX $10^{+}$ OL lineage cells that expressed GFP in Sox10-GFP/tdTom spinal cords at P13 $(86 \pm 4 \%, n=4$ mice) (Fig. $1 H$ ). Consistent with this, we found that the sum of $\mathrm{GFP}^{+}$and tdTom ${ }^{+}$cells in adult spinal cord white matter amounted to $89 \pm 3 \%$ $(n=3$ mice $)$ of all OLIG ${ }^{+}$cells, and $88 \pm$ $4 \%(n=3$ mice $)$ of all CC- $1^{+}$cells (Fig. $7 F-M)$. These data strongly suggest that we did not "lose" a significant proportion of $\mathrm{GFP}^{+}$or tdTom ${ }^{+}$cells between P13 and adulthood because expression levels fell below our level of detection. Also, almost all $\mathrm{SOX}_{10}{ }^{+}$cells in the adult were OLIG ${ }^{+}$, confirming them as $\mathrm{OL}$ lineage $[98.4 \pm 0.1 \%(n=3$ mice $)$ of all SOX $10+$ cells were OLIG ${ }^{+}$and $96.8 \pm$ $0.4 \%$ ( $n=3$ mice $)$ of all OLIG ${ }^{+}$cells were $\mathrm{SOX}_{10}{ }^{+}$in double-immunolabel experiments (Fig. $7 N-Q$ )].

\section{Discussion}

A new dual reporter system for studies of OL development and function

We have generated a new OL lineagespecific transgenic dual reporter line, Sox10-GFP/tdTom, that allows OL lineage cells to be marked by either GFP or tdTom, depending on the absence or presence of Cre recombinase. Although this reporter does not distinguish between different developmental stages of the OL lineage (because Sox10 is expressed at all stages), the inherent GFP or tdTom fluorescence before or after Cre-mediated recombination permits targeted recording from live cells or tissue slices, after which OLPs and differentiated OLs can be distinguished by dye filling through the patch pipette followed by inspection of their morphology.

Dorsally and ventrally derived OLPs are electrically similar

Since the demonstration that there are both dorsally and ventrally derived populations of OLPs in the spinal cord and brain (Spassky et al., 1998; Cai et al., 2005; Fogarty et al., 2005; Vallstedt et al., 2005; Kessaris et al., 2006), an outstanding question has been whether these are functionally identical or specialized in some way (Miller, 2005). It might reasonably have been expected that the two populations would be different, since they are specified by different signaling pathways - the ventral cells depend on SHH from the floor plate, whereas the dorsal cells are $\mathrm{SHH}$ independent. Moreover, different subtypes of OLPs and OLs have been described by a variety of criteria, including differences in the electrophysiological properties of OLPs (Káradóttir et al., 2008) in brain regions where these cells develop to produce a wide range of OL morphologies (Bakiri et al., 2011). 
Using our dual-reporter mice, we have now been able to ask whether the ventrally and dorsally derived OL lineages might correspond to different electrical subtypes. However, we could detect no significant electrophysiological differences between dOLPs and vOLPs. Both populations were an $\sim 2: 1$ mixture of cells with or without significant voltage-gated $\mathrm{Na}^{+}$current, and their input resistances were similar. Because we defined OLPs solely by their morphology in these experiments, it is possible that, in addition to true NG2-expressing OLPs that lack voltagegated $\mathrm{Na}^{+}$currents (Káradóttir et al., 2008; L. E. Clarke, K. M. Young, N. B. Hamilton, W. D. Richardson, D. R. Attwell, unpublished work), some of the $I_{\mathrm{Na}}$-negative cells we recorded were already differentiating into OLs and had downregulated NG2 and $\mathrm{Na}^{+}$channel expression before changing their morphology (De Biase et al., 2010; Etxeberria et al., 2010; Kukley et al., 2010; Vélez-Fort et al., 2010). Furthermore, we and others have found that mouse OLPs differ from rat OLPs in that their inward $\mathrm{Na}^{+}$ currents are generally smaller and correspondingly less likely to generate action potentials (De Biase et al., 2010; L. E. Clarke, K. M. Young, N. B. Hamilton, W. D. Richardson, D. R. Attwell, unpublished work). Both vOLPs and dOLPs had a similar membrane capacitance, arguing against a consistent morphological difference. vOLs and dOLs also appeared indistinguishable, having a similar membrane resistance and myelinating the same number of axons. vOLPs/vOLs and dOLPs/dOLs also reacted similarly to the neurotransmitter agonists kainate (to activate AMPA and kainate receptors), NMDA, and GABA.

\section{Tract preferences of dorsally and ventrally derived OLs}

We discovered interesting differences in the settling positions of OL lineage cells that develop from the dorsal versus the ventral $\mathrm{VZ}$ of the spinal cord. Consistent with previous studies, we confirmed that vOLPs appear around E12.5 and migrate widely throughout the cross section of the cord, populating all developing white matter tracts, including those in the dorsal funiculus, before dOLPs appear around E15.5 (for review, see Richardson et al., 2006). dOLPs were less migratory and remained mainly (though not exclusively) in the dorsal half of the cord. Strikingly, they appeared gradually to displace ventrally derived cells from dorsal axon tracts. The dorsal and dorsolateral funiculi at cervical levels contained similar numbers of ventrally and dorsally derived OL lineage cells at $\sim \mathrm{P} 13$ (e.g., $\sim 50 \%$ were ventrally derived in the RSTs and $\sim 66 \%$ in the CST) (Figs. $5 B, 6 C$ ), but, after that, dorsally derived cells took over and by P67 comprised $>80 \%$ of all OL lineage cells in the RSTs, CST, and the dorsal funiculus as a whole. The large majority of ventrally derived OL lineage cells in the dorsal funiculus were $\mathrm{CC}-1^{+}$differentiated OLs even at P13, so the fact that the absolute number of vOL lineage cells decreased after P13 while the dOL lineage did not change much (in the cervical cord at least) (Fig. 6) strongly suggests that dOLs have some selective advantage over vOLs in dorsal axon tracts. dOLs might, for example, have a higher affinity than vOLs for dorsal axons or they might respond preferentially to survival factors released by dorsal axons. The homophilic cell adhesion molecule L1CAM appears to play an especially important role in development and myelination of the CST compared to other spinal tracts (Cohen et al., 1998; Joosten and Gribnau, 1989; Dobson et al., 2001; Jakeman et al., 2006), so it is conceivable that the CST and other dorsal axons might have adhesive properties that favor dOLs over their ventral counterparts. Alternatively, there might be continual turnover of OLs in the dorsal funiculus and the dying OLs might be preferentially replaced by differentiating dOLPs. At this point, we can only speculate about the mechanism by which dOLs come to outnumber vOLs. Whatever the mechanism, there is effectively a competition between the ventral and dorsal lineages. This might be important in the context of remyelination following demyelinating disease or damage. If it turns out that dOLs are more (or less) effective at remyelinating particular tracts- or at myelinating generally-then that might influence our strategic approach to myelin regeneration.

We failed to detect $\sim 14 \%$ of OL lineage cells in the P13 spinal cord using our Sox10-GFP/tdTom reporter-i.e., $\sim 14 \%$ of SOX $10^{+}$OLPs/OLs did not express GFP in the absence of Cre. In the brain, the equivalent figure was $\sim 4 \%$. We do not know why the Sox 10 transgene is apparently inactive in a proportion of OL lineage cells, or why this proportion should be higher in the spinal cord than the brain. In the calculations above, we have made the reasonable assumption that the "missing" $\sim 14 \%$ of cells does not include a disproportionate number of either ventrally or dorsally derived OL lineage cells. If all the missing cells happened to be ventrally derived, or all happened to be dorsally derived (and if we make the assumption that the same percentage of such cells were missing at P67 as at P13), then the calculated decrease in the number of vOLs/section between P13 and P67 would still be 3.8-fold, but the final contribution of dOLs to the dorsal funiculus would be $\sim 80 \%$ or $\sim 88 \%$ of the total, respectively, rather than $\sim 85 \%$. Thus, although there is no reason to think that the missing cells should be mainly ventrally or dorsally derived, even if this were the case our conclusions would not be greatly affected.

We have previously described competition between ventrally and dorsally derived OL lineage cells in the corpus callosum and overlying cortex (Kessaris et al., 2006). In that study, we found that the fraction of OL lineage cells in the corpus callosum that was derived from the most ventral part of the forebrain VZ (Nkx2.1-expressing) started high but declined rapidly after birth, so that by P10, $<10 \%$ of OLPs/OLs in the corpus callosum (and even less in the cortex) were $N k x 2.1$ derived, and by P30, there were essentially none, their place being taken by more dorsally derived OLs (Kessaris et al., 2006). It will be interesting to discover whether there is an analogous competition between dOLs and vOLs during remyelination of experimentally induced demyelinated lesions in the brain or spinal cord and whether, for example, there is a corresponding tendency for dorsally derived OLs to dominate the remyelination process.

\section{References}

Anderson ES (2003) Morphology of early developing oligodendrocytes in the ventrolateral spinal cord of the chicken. J Neurocytol 32:1045-1053.

Anderson ES, Bjartmar C, Hildebrand C (2000) Myelination of prospective large fibres in chicken ventral funiculus. J Neurocytol 29:755-764.

Bakiri Y, Káradóttir R, Cossell L, Attwell D (2011) Morphological and electrical properties of oligodendrocytes in the white matter of the corpus callosum and cerebellum. J Physiol 589:559-573.

Bareyre FM, Kerschensteiner M, Misgeld T, Sanes JR (2005) Transgenic labeling of the corticospinal tract for monitoring axonal responses to spinal cord injury. Nat Med 11:1355-1360.

Bjartmar C, Hildebrand C, Loinder K (1994) Morphological heterogeneity of rat oligodendrocytes: electron microscopic studies on serial sections. Glia 11:235-244.

Butt AM, Colquhoun K, Tutton M, Berry M (1994) Three-dimensional morphology of astrocytes and oligodendrocytes in the intact mouse optic nerve. J Neurocytol 23:469-485.

Butt AM, Ibrahim M, Ruge FM, Berry M (1995) Biochemical subtypes of oligodendrocyte in the anterior medullary velum of the rat as revealed by the monoclonal antibody Rip. Glia 14:185-197.

Butt AM, Ibrahim M, Berry M (1997) The relationship between developing oligodendrocyte units and maturing axons during myelinogenesis in the anterior medullary velum of neonatal rats. J Neurocytol 26:327-338. 
Cai J, Qi Y, Hu X, Tan M, Liu Z, Zhang J, Li Q, Sander M, Qiu M (2005) Generation of oligodendrocyte precursor cells from mouse dorsal spinal cord independent of Nkx6 regulation and Shh signaling. Neuron 45:41-53.

Calver AR, Hall AC, Yu WP, Walsh FS, Heath JK, Betsholtz C, Richardson WD (1998) Oligodendrocyte population dynamics and the role of PDGF in vivo. Neuron 20:869-882.

Chittajallu R, Aguirre A, Gallo V (2004) NG2-positive cells in the mouse white and grey matter display distinct physiological properties. J Physiol 561:109-122.

Cohen NR, Taylor JS, Scott LB, Guillery RW, Soriano P, Furley AJ (1998) Errors in corticospinal axon guidance in mice lacking the neural cell adhesion molecule L1. Curr Biol 8:26-33.

De Biase LM, Nishiyama A, Bergles DE (2010) Excitability and synaptic communication within the oligodendrocyte lineage. J Neurosci 30:3600-3611.

del Rio-Hortega P (1921) Estudios sobre la neuroglia. La glia de escasas radiaciones oligodendroglia. Bol Real Soc Espan Hist Nat 21:63-92.

del Rio-Hortega P (1928) Tercera aportación al conocimiento morfológico e interpretación funcional de la oligodendroglia. Mem Real Soc Espan Hist Nat 14:40-122.

Dobson CB, Villagra F, Clowry GJ, Smith M, Kenwrick S, Donnai D, Miller S, Eyre JA (2001) Abnormal corticospinal function but normal axonal guidance in human L1CAM mutations. Brain 124:2393-2406.

Etxeberria A, Mangin JM, Aguirre A, Gallo V (2010) Adult-born SVZ progenitors receive transient synapses during remyelination in corpus callosum. Nat Neurosci 13:287-289.

Fogarty MH (2006) Fate-mapping the mouse neural tube by Cre-loxP transgenesis. Doctoral Thesis, University of London.

Fogarty M, Richardson WD, Kessaris N (2005) A subset of oligodendrocytes generated from radial glia in the dorsal spinal cord. Development 132:1951-1959.

Gianino S, Stein SA, Li H, Lu X, Biesiada E, Ulas J, Xu XM (1999) Postnatal growth of corticospinal axons in the spinal cord of developing mice. Brain Res Dev Brain Res 112:189-204.

Hossain-Ibrahim MK, Rezajooi K, Stallcup WB, Lieberman AR, Anderson PN (2007) Analysis of axonal regeneration in the central and peripheral nervous systems of the NG2-deficient mouse. BMC Neurosci 8:80.:80.

Jakeman LB, Chen Y, Lucin KM, McTigue DM (2006) Mice lacking L1 cell adhesion molecule have deficits in locomotion and exhibit enhanced corticospinal tract sprouting following mild contusion injury to the spinal cord. Eur J Neurosci 23:1997-2011.

Joosten EA, Gribnau AA (1989) Immunocytochemical localization of cell adhesion molecule L1 in developing rat pyramidal tract. Neurosci Lett 100:94-98.

Káradóttir R, Hamilton NB, Bakiri Y, Attwell D (2008) Spiking and nonspiking classes of oligodendrocyte precursor glia in CNS white matter. Nat Neurosci 11:450-456.

Kessaris N, Fogarty M, Iannarelli P, Grist M, Wegner M, Richardson WD (2006) Competing waves of oligodendrocytes in the forebrain and postnatal elimination of an embryonic lineage. Nat Neurosci 9:173-179.

Khattab FI (1967) Synaptic structures at nodes of Ranvier in spinal cords of mice. Nature 216:496-497.

Kleopa KA, Orthmann JL, Enriquez A, Paul DL, Scherer SS (2004) Unique distributions of the gap junction proteins connexin29, connexin32, and connexin47 in oligodendrocytes. Glia 47:346-357.

Kukley M, Capetillo-Zarate E, Dietrich D (2007) Vesicular glutamate release from axons in white matter. Nat Neurosci 10:311-320.

Kukley M, Nishiyama A, Dietrich D (2010) The fate of synaptic input to NG2 glial cells: neurons specifically downregulate transmitter release onto differentiating oligodendroglial cells. J Neurosci 30:8320-8331.

Lee EC, Yu D, Martinez de Velasco J, Tessarollo L, Swing DA, Court DL, Jenkins NA, Copeland NG (2001) A highly efficient Escherichia colibased chromosome engineering system adapted for recombinogenic targeting and subcloning of BAC DNA. Genomics 73:56-65.

Lin SC, Bergles DE (2004) Synaptic signaling between GABAergic interneurons and oligodendrocyte precursor cells in the hippocampus. Nat Neurosci 7:24-32.

Miller RH (2005) Dorsally derived oligodendrocytes come of age. Neuron $45: 1-3$.

Nery S, Wichterle H, Fishell G (2001) Sonic hedgehog contributes to oligodendrocyte specification in the mammalian forebrain. Development 128:527-540.

Pringle NP, Richardson WD (1993) A singularity of PDGF alpha-receptor expression in the dorsoventral axis of the neural tube may define the origin of the oligodendrocyte lineage. Development 117:525-533.

Richardson WD, Kessaris N, Pringle N (2006) Oligodendrocyte wars. Nat Rev Neurosci 7:11-18.

Shaner NC, Campbell RE, Steinbach PA, Giepmans BN, Palmer AE, Tsien RY (2004) Improved monomeric red, orange and yellow fluorescent proteins derived from Discosoma sp. red fluorescent protein. Nat Biotechnol 22:1567-1572.

Spassky N, Goujet-Zalc C, Parmantier E, Olivier C, Martinez S, Ivanova A, Ikenaka K, Macklin W, Cerruti I, Zalc B, Thomas JL (1998) Multiple restricted origin of oligodendrocytes. J Neurosci 18:8331-8343.

Sun T, Pringle NP, Hardy AP, Richardson WD, Smith HK (1998) Pax6 influences the time and site of origin of glial precursors in the ventral neural tube. Mol Cell Neurosci 12:228-239.

Tekki-Kessaris N, Woodruff R, Hall AC, Gaffield W, Kimura S, Stiles CD, Rowitch DH, Richardson WD (2001) Hedgehog-dependent oligodendrocyte lineage specification in the telencephalon. Development 128:2545-2554.

Vallstedt A, Klos JM, Ericson J (2005) Multiple dorsoventral origins of oligodendrocyte generation in the spinal cord and hindbrain. Neuron 45:55-67.

van Heyningen P, Calver AR, Richardson WD (2001) Control of progenitor cell number by mitogen supply and demand. Curr Biol 11:232-241.

Vélez-Fort M, Maldonado PP, Butt AM, Audinat E, Angulo MC (2010) Postnatal switch from synaptic to extrasynaptic transmission between interneurons and NG2 cells. J Neurosci 30:6921-6929.

Watson C, Paxinos G, Kayoliaglu G (2008) The spinal cord: a Christopher and Dana Reeve Foundation text and atlas. New York: Academic.

Zhang G, Gurtu V, Kain SR (1996) An enhanced green fluorescent protein allows sensitive detection of gene transfer in mammalian cells. Biochem Biophys Res Commun 227:707-711.

Ziskin JL, Nishiyama A, Rubio M, Fukaya M, Bergles DE (2007) Vesicular release of glutamate from unmyelinated axons in white matter. Nat Neurosci 10:321-330. 